\title{
Inactivation of prosurvival Bcl-2 proteins activates Bax/Bak through the outer mitochondrial membrane
}

\author{
Katelyn L. O'Neill, ${ }^{1}$ Kai Huang, ${ }^{1}$ Jingjing Zhang, ${ }^{1,2}$ Yi Chen, ${ }^{1}$ and Xu Luo ${ }^{1}$ \\ ${ }^{1}$ Eppley Institute for Research in Cancer and Allied Diseases, Fred and Pamela Buffett Cancer Center, University of Nebraska \\ Medical Center, Omaha, Nebraska 68198, USA; ${ }^{2}$ Xiangya Hospital, Central South University, Changsha 410008, China
}

The mechanism of Bax/Bak activation remains a central question in mitochondria-dependent apoptotic signaling. While it is established that all proapoptotic Bcl-2 homology 3 (BH3)-only proteins bind and neutralize the antiapoptotic Bcl-2 family proteins, how this neutralization leads to Bax/Bak activation has been actively debated. Here, genome editing was used to generate cells deficient for all eight proapoptotic $\mathrm{BH} 3$-only proteins (OctaKO) and those that lack the entire Bcl-2 family (Bcl-2 allKO). Although the OctaKO cells were resistant to most apoptotic stimuli

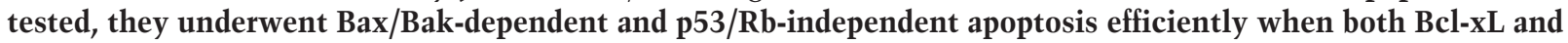
Mcl-1, two anti-apoptotic Bcl-2 proteins, were inactivated or eliminated. Strikingly, when expressed in the Bcl-2 allKO cells, both Bax and Bak spontaneously associated with the outer mitochondrial membrane (OMM) through their respective helix 9, and this association triggered their homo-oligomerization/activation. Together, these results strongly suggest that the OMM, not BH3-only proteins or $\mathrm{p53} / \mathrm{Rb}$, is the long-sought-after direct activator of Bax/Bak following BH3-only-mediated neutralization of anti-apoptotic Bcl-2 proteins.

[Keywords: anti-apoptotic Bcl-2 proteins; BH3-only; Bax/Bak activation; outer mitochondrial membrane]

Supplemental material is available for this article.

Received December 18, 2015; revised version accepted March 18, 2016.

Apoptosis, a major mode of programmed cell death, plays an essential role in development and maintenance of tissue homeostasis (Fuchs and Steller 2011). Numerous extracellular and intracellular signals induce apoptosis by triggering mitochondrial outer membrane permeabilization (MOMP), commonly considered the point of no return, through the actions of two pore-forming Bcl-2 family proteins, Bax and Bak (Wei et al. 2001; Tait and Green 2010).

The Bcl-2 family proteins, containing one or more of the Bcl-2 homology (BH) domains (BH1-4), consist of both anti- and proapoptotic members, the latter of which are further divided into the multi-BH domain effector proteins Bax and Bak and the proapoptotic $\mathrm{BH} 3$-only proteins. While the anti-apoptotic members, including Bcl-2, Bcl$\mathrm{xL}, \mathrm{Bcl}-\mathrm{w}, \mathrm{Mcl}-1$, and $\mathrm{Al}$, inhibit the activation and activities of Bax/Bak, the proapoptotic BH3-only proteins, including Bad, Bid, Bik, Bim, Bmf, Hrk, Noxa, and Puma, promote Bax/Bak activation (Youle and Strasser 2008). Once activated, both Bax and Bak form homo-oligomers on the outer mitochondrial membrane (OMM) and generate pores large enough for the escape of apoptogenic proteins, such as cytochrome $\mathrm{c}$ and SMAC, into the cyto-

Corresponding author: xuluo@unmc.edu

Article published online ahead of print. Article and publication date are online at http://www.genesdev.org/cgi/doi/10.1101/gad.276725.115. plasm, leading to apoptosome formation and caspase activation (Jiang and Wang 2004).

As critical mediators of MOMP, different subsets of BH3-only proteins become transcriptionally or post-translationally activated (i.e., tBid and Bim) in response to various stimuli and in turn trigger Bax/Bak activation (Li et al. 1998; Luo et al. 1998; Puthalakath et al. 2007). How do BH3-only proteins activate Bax and Bak? Clues seem to come from three major interactions among the Bcl-2 family proteins, established mostly through biochemical and structural studies. First, the anti-apoptotic family proteins bind and sequester Bax/Bak. The disruption of this interaction is generally considered a prerequisite step prior to Bax/Bak activation (Fletcher et al. 2008; Llambi et al. 2011). Second, the BH3-only proteins, through their $\mathrm{BH} 3$ domains, avidly bind to and inactivate the anti-apoptotic Bcl-2 family proteins. Interestingly, BH3-only proteins display vastly different affinities for various prosurvival Bcl-2 proteins (Chen et al. 2005; Willis and Adams 2005). Third, many of the proapoptotic BH3only proteins (most notably tBid, Bim, and Puma), through

(C) 2016 O'Neill et al. This article is distributed exclusively by Cold Spring Harbor Laboratory Press for the first six months after the full-issue publication date (see http://genesdev.cshlp.org/site/misc/terms.xhtml). After six months, it is available under a Creative Commons License (Attribution-NonCommercial 4.0 International), as described at http:// creativecommons.org/licenses/by-nc/4.0/. 
their BH3 domains, also transiently engage Bax/Bak, causing their conformational transformation and activation (Letai et al. 2002; Gavathiotis et al. 2008; Czabotar et al. 2013; Moldoveanu et al. 2013).

Primarily based on in vitro studies, it has been proposed that, during apoptosis, activated $\mathrm{BH}$-only proteins bind and inactivate all anti-apoptotic Bcl-2 proteins, and this inactivation liberates direct activator $\mathrm{BH} 3$-only proteins, which in turn directly bind to and activate Bax/Bak (Kim et al. 2006; Llambi et al. 2011; Moldoveanu et al. 2014). However, whether such a direct BH3-only-Bax/ Bak interaction is essential to BH3-only-mediated Bax/ Bak activation remains unclear (Garcia-Saez 2012; Borner and Andrews 2014). Meanwhile, whether the BH3-onlymediated neutralization of anti-apoptotic Bcl-2 proteins is sufficient for Bax/Bak activation is not known /Chipuk and Green 2008). In this study, using a genetic system in conjunction with put-back experiments, we sought to address these two issues and identify the direct trigger for Bax/Bak activation following inactivation of the anti-apoptotic Bcl-2 proteins.

\section{Results}

Investigating how $\mathrm{BH} 3$-only proteins activate $\mathrm{Bax} / \mathrm{Bak}$ is complicated by the fact that the direct activator $\mathrm{BH} 3-$ only proteins have two $\mathrm{BH} 3$-mediated activities: direct activation of Bax/Bak and neutralization of the anti-apoptotic Bcl-2 proteins (Chipuk and Green 2008). To evaluate the distinct roles of these two activities in vivo, we used a two-part approach that combines genetic ablation of all of the potential direct activator $\mathrm{BH} 3$-only proteins with genetic or functional inactivation of the anti-apoptotic Bcl-2 proteins.

\section{Generation of cells deficient for all eight proapoptotic BH3-only proteins (OctaKO)}

Recent data from liposome experiments demonstrated that, in addition to tBid, Bim, and Puma, some other proapoptotic $\mathrm{BH} 3$-only proteins, including Noxa, Bik, Bmf, and Hrk, were able to directly activate Bax/Bak, albeit with weaker activities (Dai et al. 2011; Du et al. 2011). To examine the requirement of direct activation by these proteins in vivo, we sought to generate cells deficient for all eight proapoptotic $\mathrm{BH} 3$-only proteins through genome editing.

HCT116 cells were first cotransfected with four CRISPR-expressing plasmids-separately targeting the genomic region upstream of the $\mathrm{BH} 3$ domains of Hrk, Bmf, Puma, and Bid-together with a RFP/GFP-HygR reporter plasmid (Fig. 1A). Following a hygromycin selection, single clones displaying a loss of both Bid and Puma proteins were isolated. These clones were further screened for the frameshift mutations of both Hrk and $\mathrm{Bmf}$ genes by genomic sequencing around the target region of the CRISPRs, as antibodies recognizing endogenous Hrk and Bmf in HCT116 cells are unavailable. One clone with homogeneous and compound heterozygous frameshift mutations in the target regions (upstream of the $\mathrm{BH} 3$ domains) of $\mathrm{Bmf}$ and $H r k$, respectively, was isolated and verified as $\mathrm{Bid}^{-1-} \mathrm{Bmf}^{-/-} \mathrm{Hrk}^{-/-} \mathrm{Puma}^{-/-}$by Western blot and genomic sequencing (Fig. 1B,C). Cells from this clone were subsequently transfected with two CRISPR plasmids targeting Bim and Noxa separately. Following a flow cytometry sorting for RFP/GFP expression from the cotransfected reporter plasmid, single clones were isolated and screened for the additional loss of Bim and Noxa proteins. Two of these clones were mixed and subjected to a third round of transient transfection with two CRISPR plasmids targeting Bik and Bad separately followed by flow cytometry. Three single clones carrying the genotype of $\mathrm{Bad}^{-/-} \mathrm{Bid}^{-/} \mathrm{Bik}^{-/-} \mathrm{Bim}^{-/} \mathrm{Bmf}^{-/-} \mathrm{Hrk}^{-/-}$ Noxa $^{-1-}$ Puma ${ }^{-/-}$(named OctaKO clones A, B, and C) were isolated and verified by Western blot and genomic sequencing (Fig. 1D; Supplemental Figs. S1,S2; Supplemental Table S1). The loss of functional Bmf and Hrk proteins in these clones was further verified by sequencing the respective cDNAs amplified from these clones (Supplemental Fig. S3). As a control, we also generated $\mathrm{Bax}^{-1-} \mathrm{Bak}^{-/-}$(DKO) HCT116 cells through CRISPRs (Fig. 1D). Not surprisingly, the DKO cells and all three OctaKO clones were highly resistant to serum starvation-, thapsigargin-, and TRAIL-induced apoptosis, as evidenced by a complete inhibition of PARP cleavage (Fig. $1 \mathrm{E})$. In addition, Annexin V staining followed by flow cytometry analysis and a clonogenic survival assay were used to further confirm the resistance of OctaKO clone A to these treatments (Fig. 1F; Supplemental Fig. S4).

\section{Efficient induction of apoptosis in the OctaKO cells following inactivation of Bcl-xL and Mcl-1}

The direct activation model suggests that, following neutralization of the anti-apoptotic members, the direct activator $\mathrm{BH} 3$-only proteins are released from sequestration and in turn directly activate Bax/Bak (Kim et al. 2006, 2009; Llambi et al. 2011). It predicts that at least one of the direct activators is necessary for Bax/Bak activation. We sought to test this hypothesis by inactivating the anti-apoptotic Bcl-2 proteins in the OctaKO cells. Through a combinatorial siRNA knockdown approach, our earlier study revealed that inactivation of Bcl-xL/Mcl-1 was sufficient to trigger Bax/Bak activation in HeLa cells (Lopez et al. 2010). Using the same strategy, the wild-type HCT116, the DKO, and the three OctaKO clones were transfected with siRNAs against Bcl-xL and Mcl-1 individually or in combination. Remarkably, the wild-type and three OctaKO clones showed robust PARP cleavage following the simultaneous knockdown of Bcl-xL and Mcl1 (Fig. 2A). To examine the requirement of Bax/Bak in this activity, CRISPR was used to eliminate Bax and Bak from OctaKO clone A. Not surprisingly, PARP cleavage was completely abolished in Octa/Bax/Bak knockout cells, indicating that apoptosis induced by the simultaneous loss of Bcl-xL and Mcl-1 was Bax/Bak-dependent (Fig. 2A). This result was also confirmed by Hoechst staining of the siRNA transfected cells (Supplemental Fig. S5)

In addition, a UV/ABT-737 combination treatment of the cells (with ABT-737 added immediately following 
A

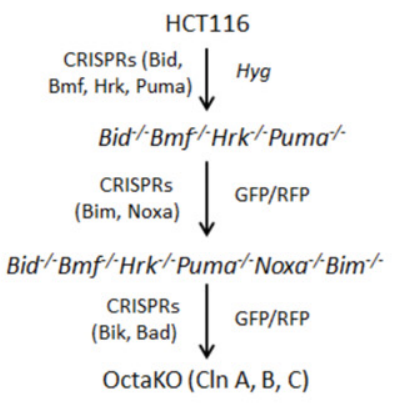

D

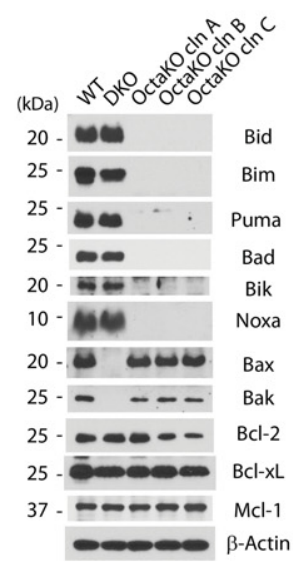

B
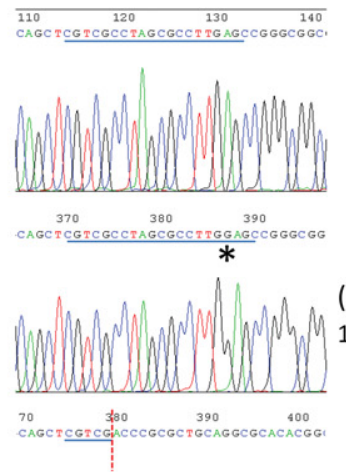

Hrk, (OctaKO, Cln A, 1bp insertion)

Hrk, (OctaKO, Cln A,

Hrk

(w.t.)

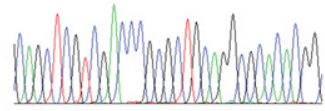

59bp deletion)
C

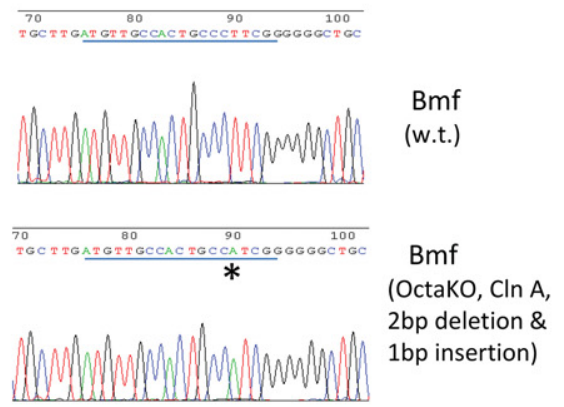

E

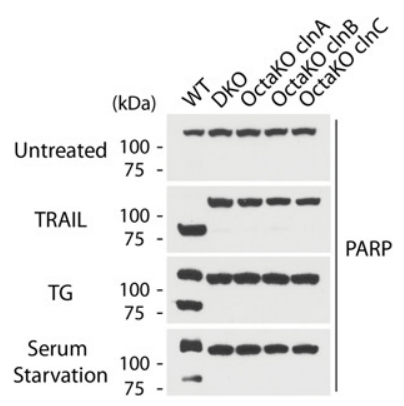

$\mathbf{F}$

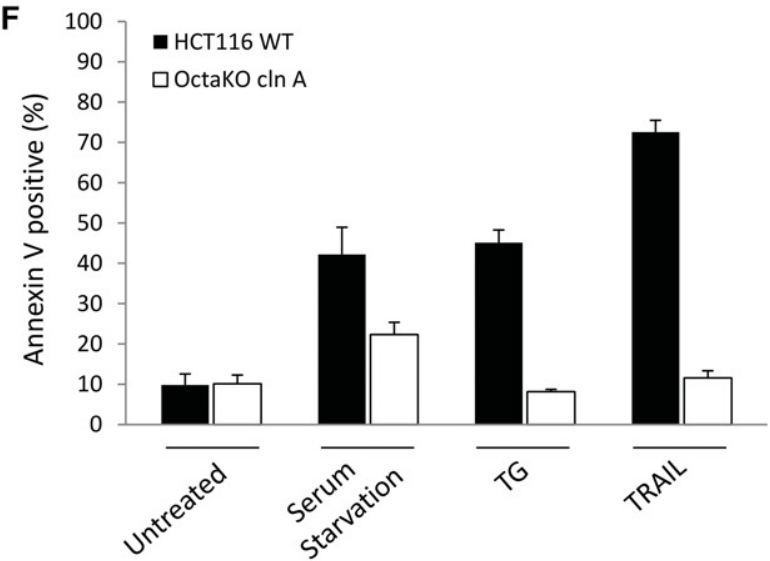

Figure 1. Generation of OctaKO cells. (A) Diagram of strategy for the generation of OctaKO cells. (B) Genomic sequences for Hrk at the targeted region (underlined). The dotted line indicates the deletion, and an asterisk indicates the 1-base-pair insertion. $(C)$ Genomic sequences for $B m f$ at the targeted region (underlined). An asterisk indicates the mutation. $(D)$ Western blot analysis of the three OctaKO clones. (E) The wild-type (WT) and mutant clones of HCT116 were treated with $25 \mathrm{ng} / \mathrm{mL}$ TRAIL for $5 \mathrm{~h}$ or $3 \mu \mathrm{M}$ thapsigargin (TG) for $24 \mathrm{~h}$ or were serum-starved for $48 \mathrm{~h}$. Following each treatment, cell lysates were Western-blotted against an anti-PARP antibody. A representative of three independent experiments is shown. Following each treatment, cell lysates were harvested for Western blot with an anti-PARP antibody. $(F)$ Following each treatment as described in $E$, cells were stained by Annexin $\mathrm{V}$ and analyzed by flow cytometry. The results are the mean \pm SEM of at least three independent experiments.

UV treatment) was used as an alternative way to eliminate/inactivate both Mcl-1and Bcl-xL. While UV is known to induce a rapid, proteasome-mediated elimination of Mcl-1 (Nijhawan et al. 2003), ABT-737 is a highly specific and potent small molecule inhibitor of Bcl-xL/ Bcl-2/Bcl-w (Oltersdorf et al. 2005). Indeed, $5 \mathrm{~h}$ after UV treatment, Mcl-1 was essentially eliminated from wildtype, DKO, and OctaKO cells (Supplemental Fig. S6). While both single treatments caused a modest level of apoptosis in wild-type cells but not in OctaKO cells, the combined treatment caused robust apoptosis in both wild-type and OctaKO cells but not in DKO or Octa/ Bax/Bak knockout cells (Fig. 2B,C). Together, these results demonstrate that inactivation of both Bcl-xL and Mcl-1 is sufficient for Bax/Bak activation in the absence of the proapoptotic $\mathrm{BH} 3$-only proteins.

However, the above conclusion does not exclude the possibility that, once released from sequestration by the anti-apoptotic family proteins, the direct activator $\mathrm{BH} 3$ only proteins may accelerate Bax/Bak activation by engaging Bax/Bak. We therefore sought to compare the kinetics of Bax/Bak activation or apoptosis in the wild-type and OctaKO cells following the inactivation/elimination of Bcl-xL and Mcl-1. Due to its slow kinetics, siRNA knockdown was not suitable for this effort. To circumvent this difficulty, we resorted to inactivating the Mcl-1 gene in both the wild-type and OctaKO cells and assessing the kinetics of apoptosis following the addition of the fastacting Bcl-xL/Bcl-2/Bcl-w inhibitor ABT-737. We therefore generated Mcl-1 knockout and Octa/Mcl-1 knockout HCT116 cells by transfecting the wild-type HCT116 cells and OctaKO clone A with a CRISPR plasmid against Mcl-1 (Fig. 2D,E). Two Mcl-1 knockout clones and two Octa/ Mcl-1 knockout clones were isolated and verified by Western blot and genomic sequencing (Fig. 2F; Supplemental Fig. S7). As expected, TRAIL or thapsigargin treatments 
O'Neill et al.

A

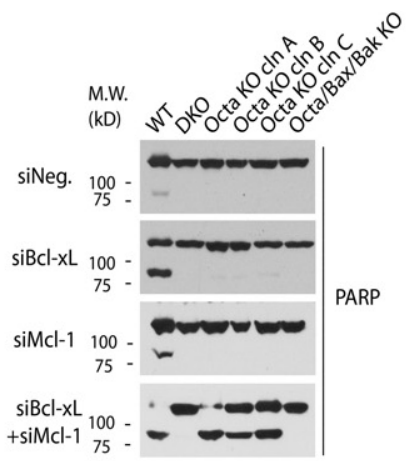

B

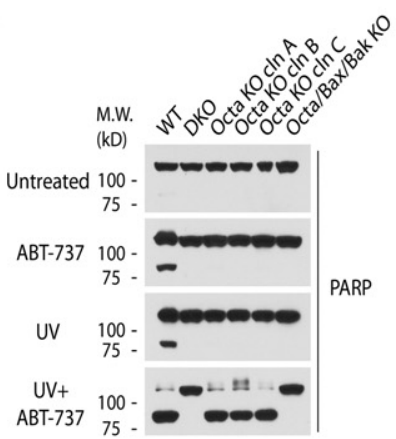

C

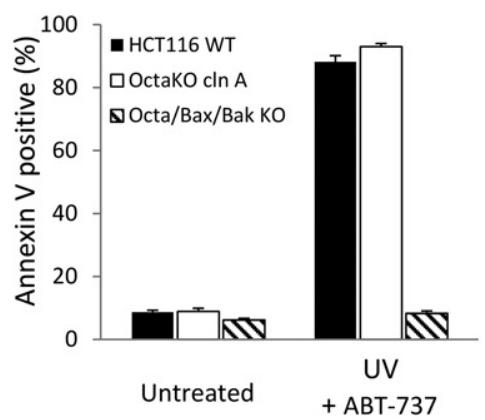

D

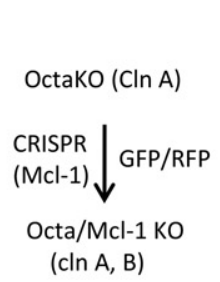

E

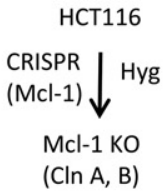

$\mathbf{F}$

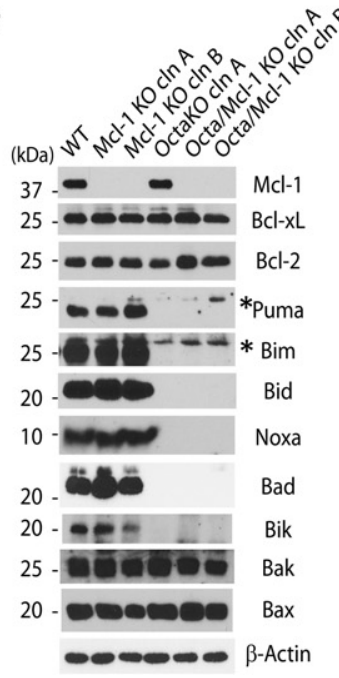

G

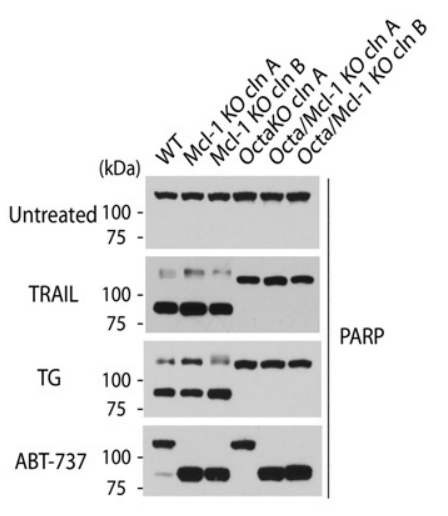

H

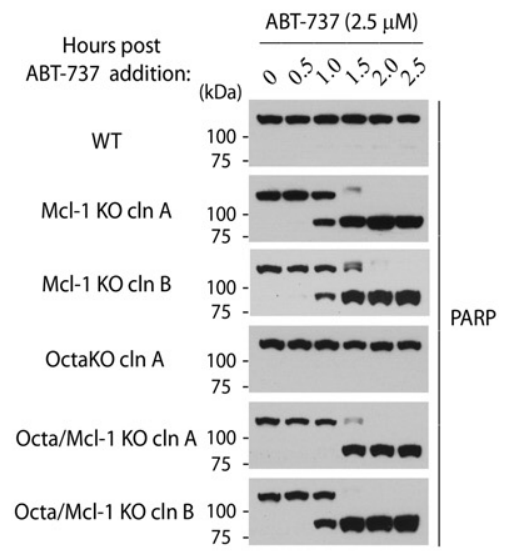

Figure 2. Suppression of Bcl-xL and Mcl-1 efficiently induces apoptosis in OctaKO cells. (A) Cell lysates were harvested following siRNA transfection as in $B$ and Western-blotted with anti-PARP antibody. (B) Cells were treated with either $500 \mathrm{~J} / \mathrm{M}^{2} \mathrm{UV}, 2.5 \mu \mathrm{M}$ ABT-737, or both. Sixteen hours later, cell lysates were harvested and Western-blotted with anti-PARP antibody. (C) Cells treated by the combination of UV and ABT-737 for $16 \mathrm{~h}$ were stained with Annexin V and analyzed by flow cytometry. Each data point is an average of at least three independent experiments. (D) Strategy for the generation of OctaKO/Mcl-1 knockout (KO) clones. (E) Strategy for the generation of Mcl-1 knockout HCT116 cells. $(F)$ Western blot of the cell lysates of the indicated cell lines with the indicated antibodies. An asterisk indicates a nonspecific protein. $(G)$ Cells were treated with $25 \mathrm{ng} / \mathrm{mL}$ TRAIL for $5 \mathrm{~h}, 3 \mu \mathrm{M}$ thapsigargin (TG) for $24 \mathrm{~h}$, or $2.5 \mu \mathrm{M}$ ABT-737 for $2 \mathrm{~h}$ and harvested for Western blot with anti-PARP antibody. $(H)$ ABT-737 $(2.5 \mu \mathrm{M})$ was added to the indicated cell lines, which were harvested at the indicated time points for Western blot with anti-PARP antibody.

induced strong apoptosis in the wild-type and the Mcl-1 knockout cells but not in the OctaKO or Octa/Mcl-1 knockout cells (Fig. 2G). Strikingly, while the addition of ABT-737 induced a very low level of apoptosis in the wild-type cells and no apoptosis in the OctaKO cells, robust apoptosis was observed in both the Mcl-1 knockout cells and the Octa/Mcl-1 knockout cells within $2 \mathrm{~h}$ (Fig. 2G; Supplemental Fig. S8). To examine the kinetics of apoptosis, cells were harvested at different time points following the addition of ABT-737 and analyzed for PARP cleavage and a caspase $3 / 7$ substrate assay. The two clones of Mcl-1 knockout and two clones of Octa/Mcl-1 knockout cells displayed similar kinetics of caspase activation (Fig. 2H; Supplemental Fig. S9), suggesting that loss of the proapoptotic $\mathrm{BH} 3$-only proteins does not significantly affect Bax/Bak activation following inactivation of both Bcl-xL and Mcl-1.
Apoptosis in the absence of the proapoptotic BH3-only proteins, $p 53$, and $R b$

The above results suggested that the neutralization function of the $\mathrm{BH} 3$-only proteins is sufficient to trigger Bax/ Bak activation. How does inactivation of the anti-apoptotic Bcl-2 proteins then lead to the activation of Bax and Bak? As both tumor suppressors p53 and Rb have been shown to engage and activate Bax/Bak in in vitro studies (Chipuk et al. 2004; Hilgendorf et al. 2013), it is possible that they directly activate Bax and Bak in the OctaKO cells following Bcl-xL/Mcl-1 inactivation. To test this possibility, two pairs of nickase-expressing plasmids (Mali et al. 2013; Ran et al. 2013a) targeting the $p 53$ gene and the $R b 1$ gene separately were constructed and cotransfected into the OctaKO cells together with the RFP/GFP-HygR reporter plasmid (Fig. 3A). Following a 
A

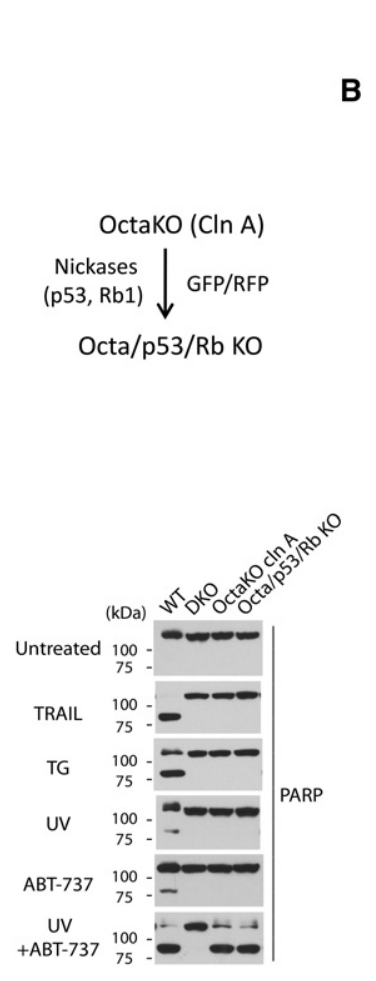

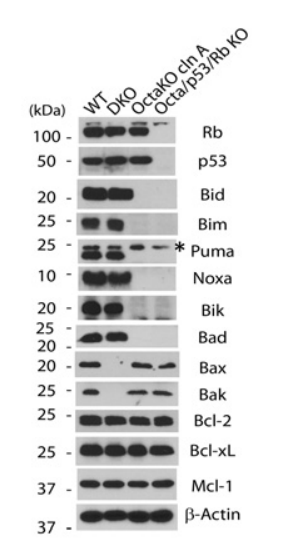

C

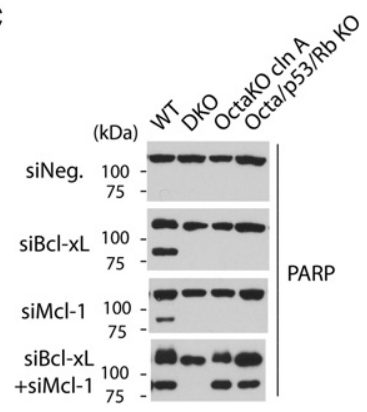

E

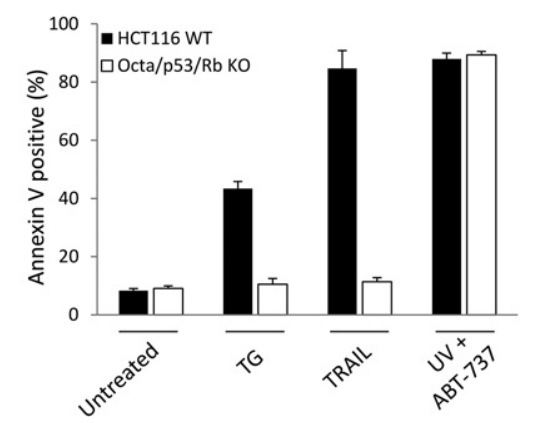

Figure 3. BH3-only and p53/Rb-independent apoptosis following inactivation of Bcl-xL and Mcl-1. (A) Diagram for the generation of Octa/p53/Rb1 knockout (KO) cells. (B) Western blot of the indicated cell lines. An asterisk indicates a nonspecific protein. $(C)$ Cells were harvested following siRNA transfection for Western blot with anti-PARP antibody. $(D)$ Cells were treated with $25 \mathrm{ng} / \mathrm{mL}$ TRAIL for $5 \mathrm{~h}, 3 \mu \mathrm{M}$ thapsigargin (TG) for $24 \mathrm{~h}, 2.5 \mu \mathrm{M}$ ABT-737 for 16 h, $500 \mathrm{~J} / \mathrm{M}^{2} \mathrm{UV}$, or a combination of $500 \mathrm{~J} /$ $\mathrm{M}^{2}$ UV and $2.5 \mu \mathrm{M}$ ABT-737 for 16 h. Following the indicated treatments, cell lysates were generated for Western blot with anti-PARP antibody. (E) Cells were treated by TRAIL, thapsigargin, or the combination of UV and ABT-737 as described in $D$ and were stained with Annexin $\mathrm{V}$ followed by flow cytometry analysis. The results are the mean \pm SEM of at least three independent experiments.
GFP/RFP sorting, a single clone of Octa/p53/Rb knockout cells was isolated and validated by Western blot and genomic sequencing (Fig. 3B; Supplemental Fig. S10). While siRNA knockdown of Bcl-xL or Mcl-1 individually had little effect on the Octa/p53/Rb knockout cells, the double siRNA transfection induced robust apoptosis (Fig. 3C; Supplemental Fig. S11). In addition, while the Octa/p53/ $\mathrm{Rb}$ knockout cells were completely resistant to TRAIL, thapsigargin, UV, or ABT-737 treatments, the UV/ABT737 combination treatment induced robust apoptosis (Fig. 3D,E; Supplemental Fig. S12), indicating that endogenous $\mathrm{p} 53$ and $\mathrm{Rb}$ are not involved in Bax/Bak activation in the OctaKO cells when both Bcl-xL and Mcl-1 are inactivated.

\section{Suppression of Bcl-xL and Mcl-1 activates Bax in the} absence of potential direct activator BH3-only proteins

Although normally existing as a monomeric, inactive, and cytosolic protein, Bax moves to the mitochondria and forms homo-oligomers on the OMM following apoptotic stimulation (Hsu et al. 1997b; Walensky and Gavathiotis 2011). The mechanism of this translocation remains not well understood. To examine whether suppression of the anti-apoptotic Bcl-2 family proteins can induce the mitochondrial translocation of Bax, we sought to carry out a "put-back" experiment in which GFP-Bax is expressed in cells without Bax/Bak and the proapoptotic BH3-only proteins. Bax and Bak proteins were eliminated from the Octa/Mcl-1 knockout cells by transiently transfecting the Octa/Mcl-1 knockout cells with two CRISPR-expressing plasmids against $B a x$ and Bak separately followed by flow cytometry sorting and single-clone screening. A single clone of Octa/Mcl-1/Bax/Bak knockout cells was isolated (Supplemental Fig. S13), retrovirally infected, and subsequently sorted by flow cytometry for the stable expression of either GFP or GFP-Bax (Fig. 4A). The level of GFP-Bax expression in the resulting pool was comparable with the level of endogenous Bax in wild-type HCT116 cells (Fig. 4B). The addition of ABT-737 resulted in robust apoptosis in Octa/Mcl-1/Bax/Bak knockout cells expressing GFP-Bax but not in those expressing GFP, indicating that the GFP-Bax in these cells was fully functional (Fig. 4C; Supplemental Fig. S14). Not surprisingly, while GFP-Bax is predominantly cytosolic in the Octa/Mcl-1/ Bax/Bak knockout cells under normal conditions, it efficiently moved to the mitochondria within $3 \mathrm{~h}$ following the addition of ABT-737 (Fig. 4D), indicating that suppression of anti-apoptotic Bcl-2 family proteins is sufficient to cause Bax translocation in the absence of the proapoptotic BH3-only proteins.

Among the eight proapoptotic $\mathrm{BH} 3$-only proteins, Bad is the only widely accepted sensitizer due to its selective binding to Bcl-xL, Bcl-2, and Bcl-w but not Mcl-1, Al, or Bax/Bak (Chen et al. 2005; Llambi et al. 2011). If suppression of Bcl-xL and Mcl-1 by the $\mathrm{BH} 3$-only proteins is sufficient to induce Bax/Bak activation, forced expression of Bad in cells with inactivated Mcl-1 should induce apoptosis without the need for other $\mathrm{BH} 3$-only proteins. To test this possibility, a plasmid expressing GFP-Bad (human) or its $\mathrm{BH} 3$ mutant, $\mathrm{Bad}^{\mathrm{L} 114 \mathrm{E}}$, was transfected into either the OctaKO or the Octa/Mcl-1 knockout cells. Indeed, expression of G-Bad induced apoptosis in Octa/Mcl-1 knockout cells but not in OctaKO cells (Fig. 4E). Not surprisingly, the $\mathrm{BH} 3$ mutant G-Bad ${ }^{\mathrm{L} 114 \mathrm{E}}$ failed to induce apoptosis in the Octa/Mcl-1 knockout cells. 


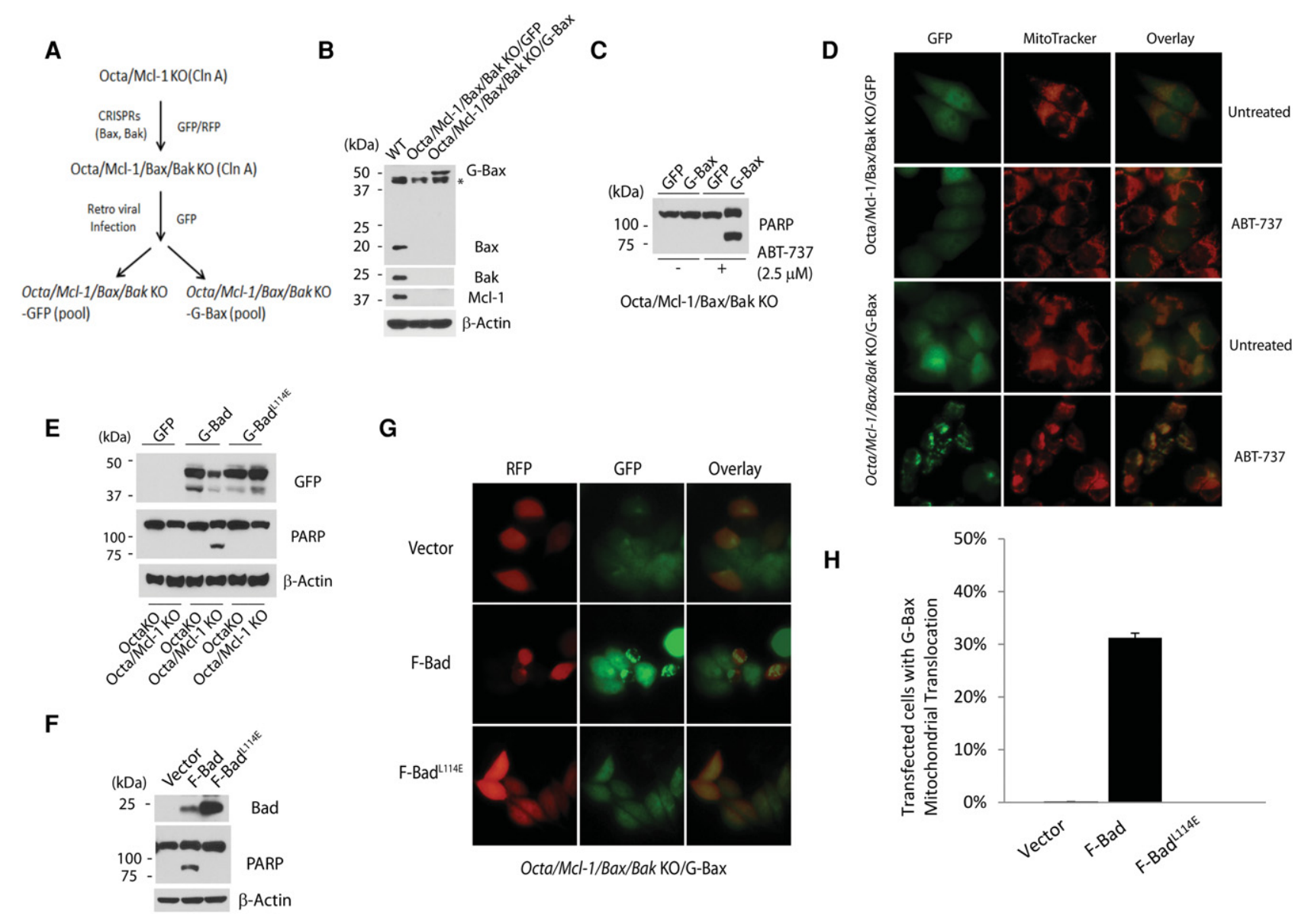

Octa/Mcl-1/Bax/Bak KO/G-Bax

Figure 4. Suppression of anti-apoptotic Bcl-2 proteins triggers mitochondrial translocation of Bax and apoptosis in the OctaKO cells. $(A)$ Diagram for generating GFP-Bax put-back Octa/Mcl-1/Bax/Bak knockout (KO) cells. (B) Expression level of GFP-Bax in the indicated cells. Cell lysates were Western-blotted against an anti-Bax antibody. An asterisk indicates a nonspecific protein. $(C, D)$ The sorted pools were treated with $2.5 \mu \mathrm{M}$ ABT-737. Six hours later, cells were harvested for Western blot against PARP $(C)$ or stained with MitoTracker $(D)$ and photographed under a fluorescence microscope. $(E)$ Transient transfection of plasmids expressing GFP-Bad or its BH3 domain mutant $\mathrm{Bad}^{\mathrm{L} 114 \mathrm{E}}$ in the indicated cell lines. Twenty hours after transfection, cells were harvested for Western blot analysis. $(F)$ Transient expression of Flag-Bad and its BH3 mutant (F-Bad $\left.{ }^{\mathrm{L} 114 \mathrm{E}}\right)$ in the indicated cells followed by Western blot analysis. (G) Octa/Mcl-1/Bax/Bak knockout/GFP-Bax cells were cotransfected with an RFP-expressing plasmid (pDsRed) and a plasmid expressing the GFP vector, GFP-Bad, or GFP-Bad ${ }^{\mathrm{L} 114 \mathrm{E}}$. Cells were photographed under a fluorescence microscope. $(H)$ Quantification of the cells that displayed GFP-Bax mitochondrial translocation among the transfected cells as described in the Materials and Methods. The values are the average of two independent experiments with error of the mean.

To examine the ability of Bad to induce Bax activation, the stable pools of Octa/Mcl-1/Bax/Bak knockout/GFPBax cells were transfected with a plasmid expressing Flag-Bad or its BH3 mutant, Flag-Bad ${ }^{\mathrm{L} 114 \mathrm{E}}$, together with a RFP-expressing plasmid (pDsRed) as a marker for transfected cells. Not surprisingly, the transient expression of wild-type Bad, but not Bad ${ }^{\mathrm{L114E}}$, resulted in apoptosis in these cells (Fig. 4F; Supplemental Fig. S15). In the presence of the pan-caspase inhibitor z-VAD, expression of F-Bad, but not F-Bad ${ }^{\mathrm{L} 114 \mathrm{E}}$, caused a mitochondrial translocation of G-Bax (Fig. 4G). Quantification showed that while $>30 \%$ of cells transfected with F-Bad-expressing plasmid displayed punctate GFP staining (an indication of the mitochondrial translocation of GFP-Bax), none was observed in cells transfected with either vector or the plasmid ex- pressing F-Bad ${ }^{\mathrm{L} 114 \mathrm{E}}$, suggesting that Bad expression is sufficient to activate GFP-Bax in these cells (Fig. 4H).

Together, these results establish that inactivation of the anti-apoptotic Bcl-2 proteins causes the activation of Bax/ Bak independently of the proapoptotic $\mathrm{BH} 3$-only proteins, $\mathrm{p} 53$, and $\mathrm{Rb}$. What, then, is the direct trigger for Bax/Bak activation?

Generation of Bcl-2 allKO cells (cells that lack the entire Bcl-2 family) and the constitutive activities of Bax/Bak

The challenge in elucidating the mechanism of Bax/Bak activation largely stems from the complex interactions among the Bcl-2 family members and the uncertainty of whether Bax/Bak exist as inactive molecules without 
the interference from the BH3-only proteins and the anti-apoptotic Bcl-2 proteins. We therefore sought to generate cells deficient for all Bcl-2 family proteins and then examine the behavior of Bax/Bak in such a cellular environment.

Using the OctaKO cells as a starting point, CRISPR plasmids against the remaining Bcl-2 family proteins (Bcl-2, Bcl-xL, Mcl-1, Bcl-w, A1, Bnip3, Nix, Bax, and Bak) were constructed and transiently transfected into OctaKO clone B in three successive rounds (each round involving three CRISPR plasmids) followed by a flow cytometry sorting for GFP/RFP signals from the cotransfected reporter plasmid and the isolation of single clones of the desired loss of the target proteins (Fig. 5A). Following the last round of transfection/sorting, single clones were isolated and screened for the disruption of the $A 1$ gene in the CRISPR target site and the loss of the Bcl-xL and Nix proteins. Finally, two clones of HCT116 cells deficient for the 10 BH3-only proteins (Bad, Bik, Puma, Hrk, Bmf, Bid, Bim, Noxa, Bnip3, and Nix), five anti-apoptotic Bcl-2 proteins (Bcl-2, Bcl-xL, Mcl-1, Bcl-w, and A1), and $\mathrm{Bax} / \mathrm{Bak}$ were isolated and named the Bcl-2 allKO cells (Fig. 5A). The loss of 14 of the target proteins was confirmed by Western blot (Fig. 5B). The genetic alterations in the CRISPR targeted region for each gene of the Bcl-2 family were confirmed by DNA sequencing (Fig. 5C; Supplemental Fig. S16; Supplemental Table S1). The Bcl2 allKO cells do not undergo spontaneous apoptosis and show distribution of cell cycle stages and proliferation curves similar to those of the wild-type HCT116 cells, indicating that the entire Bcl-2 network is not necessary for survival and proliferation (Fig. 5D; Supplemental Fig. S17). As expected, these cells did not undergo apoptosis following treatment by TRAIL or the UV/ABT-737 combination (Fig. 5D; Supplemental Fig. S18).

To examine the behavior of Bax and Bak in the Bcl-2 allKO cells, GFP-Bax or GFP-Bak was individually expressed at increasing amounts by transient transfection of both clone A and clone B. Although G-Bax or G-Bak was hardly detected across the range of DNA amounts used in the transfections, both proteins caused robust apoptosis, which was mostly inhibited by the addition of the pan-caspase inhibitor z-VAD (Fig. 5E,F; Supplemental Figs. S19, S20). As a comparison, a similar transfection was carried out in Bax/Bak DKO cells. Unlike in Bcl-2 allKO cells, despite modest apoptosis after transfection, both G-Bax and G-Bak were readily detected without the addition of $z$-VAD, indicating a significant accumulation of these proteins in the DKO cells before the onset of apoptosis (Supplemental Fig. S21). As expected, mutations in $\mathrm{Bax}$ or Bak in the respective $\mathrm{BH} 3$ domains of G-Bax or G-Bak completely abolished the killing in Bcl-2 allKO cells (Fig. 5E,F; Supplemental Figs. S19, 20). Together, these results indicate that, when expressed in the Bcl-2 allKO cells, both Bax and Bak are constitutively active.

To examine the constitutive activities of the expressed $\mathrm{Bax} / \mathrm{Bak}$ in Bcl-2 allKO cells in an inducible fashion, we established a tetracycline (Tet)-inducible system (pRetro-Tet-on) for the expression of GFP-Bax or GFP-Bak in both the DKO and Bcl-2 allKO cells. Not surprisingly,
$6 \mathrm{~h}$ after doxycycline (Dox)-induced expression of G-Bax or G-Bak, robust apoptosis was detected in Bcl-2 allKO cells when G-Bax and G-Bak were barely detectable (Fig. 5G). In contrast, little apoptosis was observed at $6 \mathrm{~h}$ after the addition of Dox when significant amounts of G-Bax and G-Bak had accumulated in the DKO cells. To ascertain that the spontaneous activation of Bax or Bak in these cells was not due to the GFP tag, we established Dox-inducible Bcl-2 allKO cell lines that express untagged Bax or Bak. The Dox-inducible expression of Bax or Bak caused robust apoptosis even when these proteins were expressed at extremely low levels (Fig. 5H,I). Together, these results strongly suggest that, upon neutralization of the anti-apoptotic Bcl-2 proteins, Bax and Bak become activated spontaneously without the help from any BH3-only proteins.

When expressed in the Bcl-2 allKO cells, both Bax and Bak spontaneously associate with the OMM, and this association triggers their homo-oligomerization

To monitor the subcellular localization of G-Bax and G-Bak in the Bcl-2 allKO cells, we induced the expression of G-Bax and G-Bak by Dox in the presence of $z$-VAD and observed cells through fluorescence microscopy. At all time points, all GFP-Bax- or GFP-Bak-expressing cells displayed a punctate staining that colocalized with TOM20, an OMM marker (Fig. 6A). It is worth noting that the mitochondrial staining for both G-Bax and G-Bak coalesced, suggesting that Bax/Bak formed homooligomers on the mitochondria. The spontaneous mitochondrial localization of both Bax and Bak strongly suggests that Bax, similar to Bak, is inherently a membrane protein in the absence of other Bcl-2 family proteins. The differential localization of Bax and Bak under normal circumstances is therefore likely due to the presence of the anti-apoptotic Bcl-2 proteins. Indeed, in DKO cells carrying the G-Bax/Bak tet-inducible system, G-Bak localized to the mitochondria, whereas G-Bax is predominantly cytosolic following the addition of Dox (Fig. 6A).

To monitor the homo-oligomerization of G-Bax and G-Bak in the Bcl-2 allKO cells, gel filtration analysis was carried out in the presence of $2 \%$ CHAPS. While both G-Bax and G-Bak formed high-order homo-oligomers after Dox-induced expression, homo-oligomer formation was essentially abolished when an untagged Bcl-xL was constitutively expressed in these cells (Fig. 6B). These results suggest that Bax and Bak spontaneously form homo-oligomers in the absence of other Bcl-2 family members and that the anti-apoptotic Bcl-2 proteins actively suppress this tendency.

The spontaneous mitochondrial association and homooligomerization of Bax and Bak in the Bcl-2 allKO cells also suggests that the OMM may serve as the direct activator of Bax/Bak. To test this hypothesis, we generated truncation mutants of Bax and Bak that lack the C-terminal transmembrane domains (TM; helix 9) and tested their mitochondrial association and homo-oligomerization in Bcl-2 allKO cells (Fig. 6C). As expected, when expressed in Bcl-2 allKO cells following induction by Dox, unlike the wild-type proteins, both G-Bax $\Delta \mathrm{TM}$ and G-Bak $\Delta \mathrm{TM}$ 
A

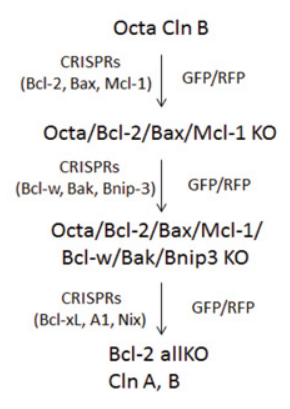

B
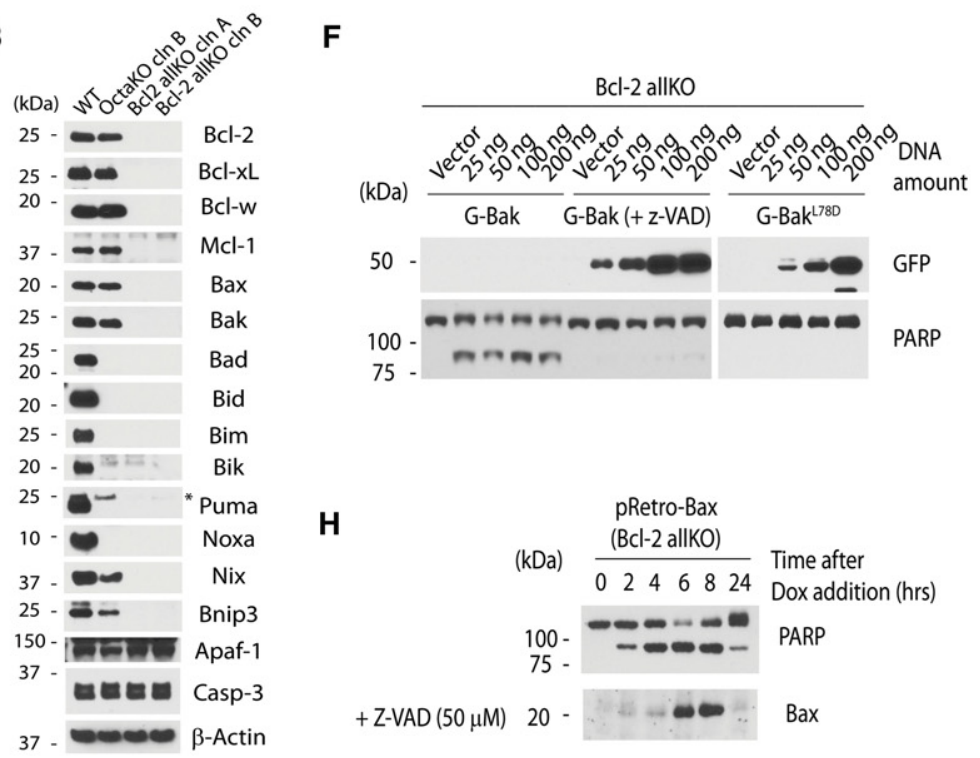

C

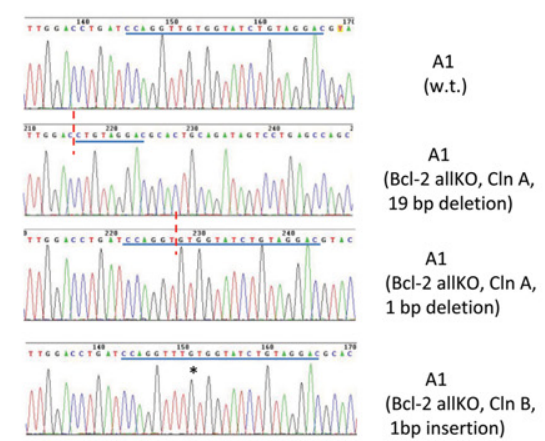

F

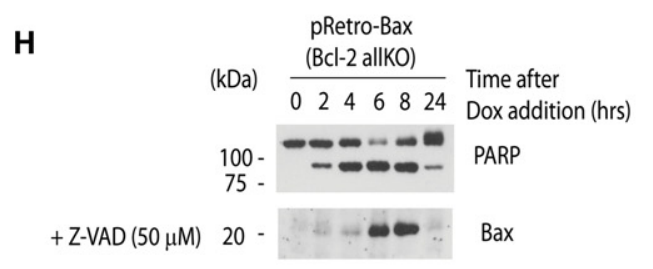

D

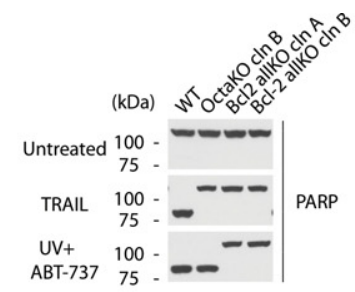

E

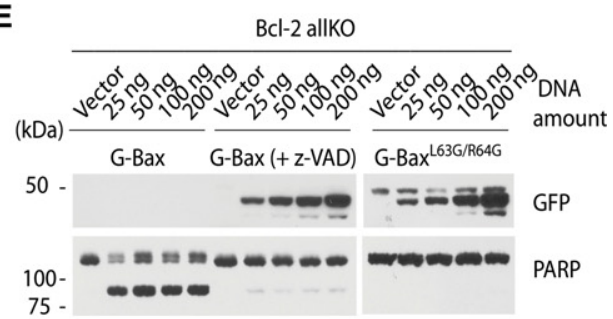

G

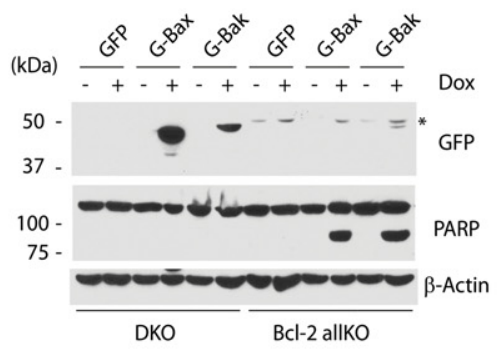

I

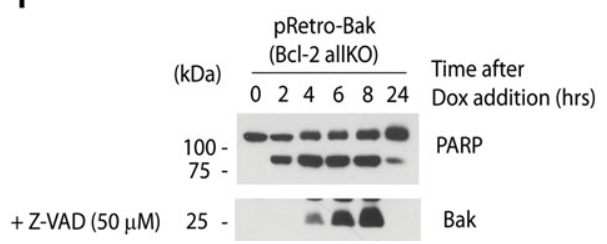

Figure 5. Generation of Bcl-2 allKO cells and the constitutive activities of Bax/Bak. (A) Diagram of strategy for the generation of Bcl-2 allKO cells. $(B)$ Western blot analysis of the wild-type (WT), OctaKO clone (cln) B, and two Bcl-2 allKO clones for Bcl-2 family proteins. The asterisk indicates a nonspecific protein. $(C)$ Genomic sequences for $A 1$ at the targeted region (underlined). The dotted line indicates a deletion, and the asterisk indicates an insertion. $(D)$ The wild-type and mutant clones of HCT116 were treated with $25 \mathrm{ng} / \mathrm{mL}$ TRAIL for $5 \mathrm{~h}$ or a combination of $500 \mathrm{~J} / \mathrm{M}^{2} \mathrm{UV}$ and $2.5 \mu \mathrm{M}$ ABT-737 for $16 \mathrm{~h}$. Following each treatment, cell lysates were Western-blotted against PARP. A representative of two independent experiments is shown. $(E, F)$ Bcl-2 allKO clone B grown in 35-mm plates were transiently transfected with plasmids expressing GFP fusion proteins of wild-type Bax, Bak with or without z-VAD-fmk, and their respective BH3 mutants. Sixteen hours after transfection, whole-cell lysates were harvested for Western blotting against GFP or PARP. (G) DKO and Bcl-2 allKO cells carrying the tetracycline (Tet)-inducible expression system for GFP, G-Bax, or G-Bak were induced by the addition of $2 \mu \mathrm{g} / \mathrm{mL}$ doxycycline (Dox). Six hours after induction, cells were harvested for Western blot analysis. $(H, I)$ Bcl-2 allKO cells carrying the Tet-inducible expression system for $\operatorname{Bax}(H)$ or Bak $(I)$ were induced by $2 \mu \mathrm{g} / \mathrm{mL}$ Dox. At the indicated time points after induction, cells were harvested for Western blot analysis.

displayed apparent cytosolic staining and were present as monomers or dimers in gel filtration in CHAPS, indicating that helix 9 is required for homo-oligomerization, a hallmark and a critical step in Bax/Bak activation (Fig. 6D,E).

To further examine the causal relationship between mitochondrial association and homo-oligomerization of $\mathrm{Bax} / \mathrm{Bak}$, we generated chimeric proteins that attached the helix 9 of Bcl-xL (amino acids 214-233), a well-defined mitochondrial targeting sequence, to the $\operatorname{Bax} \Delta \mathrm{TM}$ and BaksTM mutants (Kaufmann et al. 2003). Similar to wild-type Bax and Bak, both chimeric proteins spontaneously localized to the OMM and formed homo-oligomers in the Bcl-2 allKO cells (Fig. 6D,E). In contrast, both chi- meric proteins predominantly exist as monomer or dimers when expressed in DKO cells (Supplemental Fig. S22). These results suggested that mitochondrial association is sufficient to trigger Bax/Bak homo-oligomerization in these cells (Fig. 6E). As expected, while the $\Delta \mathrm{TM}$ mutants completely lost the apoptotic activities, the wildtype $\mathrm{Bax} / \mathrm{Bak}$ and their chimeric proteins with $\mathrm{Bcl}-\mathrm{xL}$ helix 9 efficiently caused apoptosis in Bcl-2 allKO cells even when their levels were barely detectable (Fig. 6F; Supplemental Fig. S23). In contrast, when wild-type Bax/ Bak and their mutants were expressed in the DKO cells, no or a modest level of apoptosis was observed following strong expression (Fig. 6G). Together, these results 
A

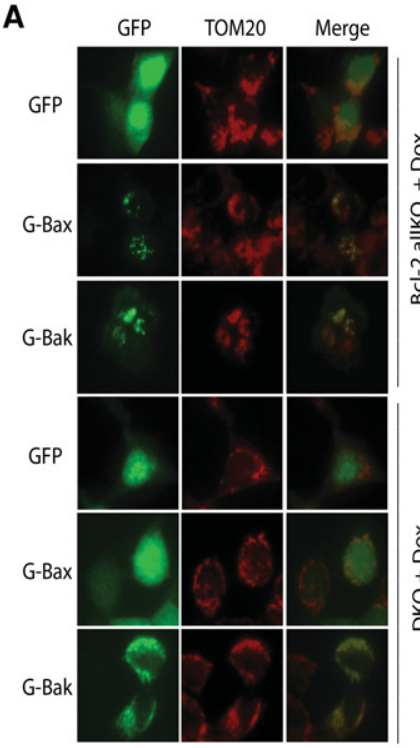

B

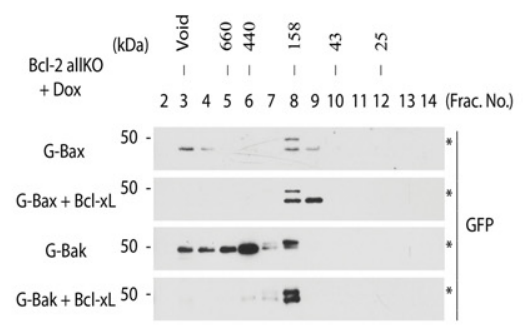

C

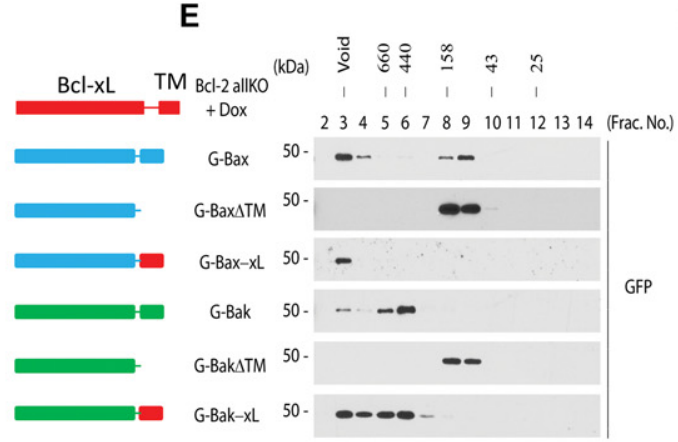

D

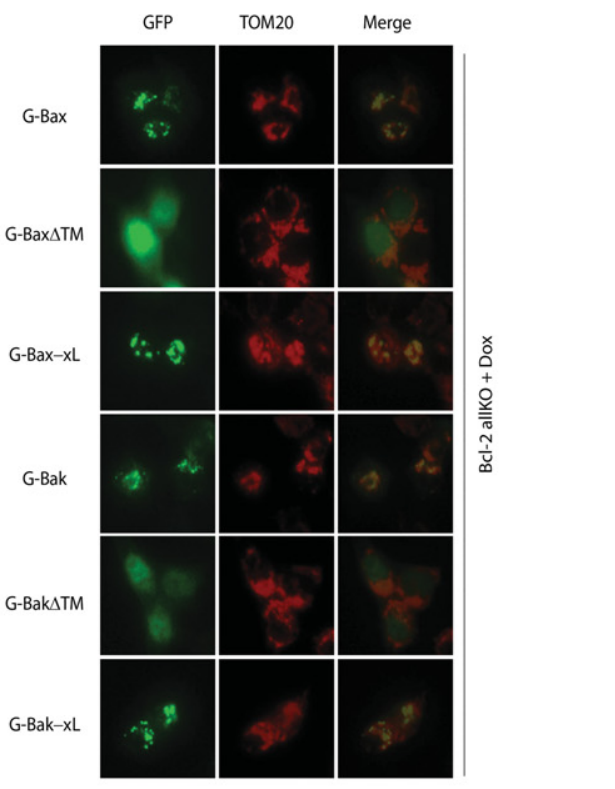

$\mathbf{F}$

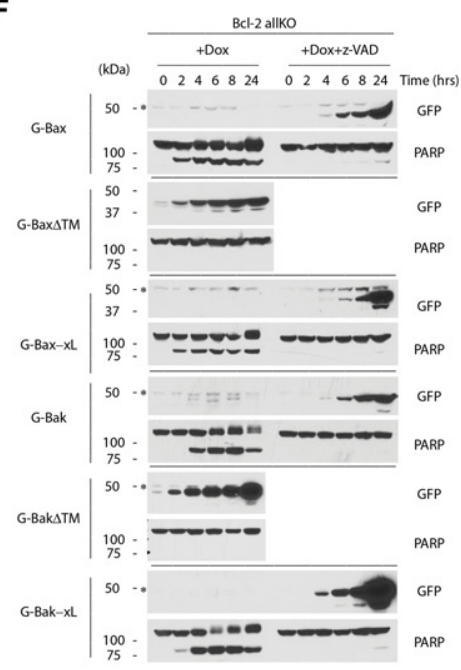

G

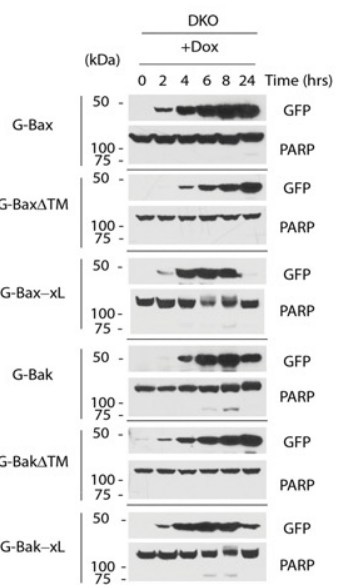

Figure 6. Mitochondrial association-dependent spontaneous homo-oligomerization of Bax/Bak in Bcl-2 allKO cells. $(A)$ Spontaneous mitochondrial targeting of Bax and Bak in Bcl-2 allKO cells. Bcl-2 allKO and Bax/Bak DKO cells carrying the Tet-on system expressing GFP, G-Bax, or G-Bak were treated with $2 \mu \mathrm{g} / \mathrm{mL}$ Dox for $8 \mathrm{~h}$ before being fixed and stained for TOM20. $\mathrm{z}$-VAD (50 $\mu \mathrm{M})$ was added to the Bcl-2 allKO cells expressing G-Bax or G-Bak to prevent apoptosis and allow detection of the protein. (B) Bcl-2 allKO cells carrying the Tet-on system expressing G-Bax or G-Bak were induced with $2 \mu \mathrm{g} / \mathrm{mL}$ Dox in the presence of $50 \mu \mathrm{M} \mathrm{z}$-VAD. The same cells were infected with a retrovirus constitutively expressing Bcl-xL and were induced with $2 \mu \mathrm{g} / \mathrm{mL}$ Dox. Sixteen hours after Dox induction, cells were solubilized in buffer A $\left(20 \mathrm{mM}\right.$ HEPES-KOH, $10 \mathrm{mM} \mathrm{KCL}, 1.5 \mathrm{mM} \mathrm{MgCl}_{2}, 1 \mathrm{mM}$ sodium EDTA, $1 \mathrm{mM}$ sodium EGTA, 1 mM dithiothreitol [DTT], $0.1 \mathrm{PMSF}, 5 \mathrm{mg} / \mathrm{mL}$ pepstatin A, $10 \mathrm{mg} / \mathrm{mL}$ leupeptin) with $2 \%$ CHAPS. Cell lysates were fractionated on a Superdex $200 \mathrm{column}$. Each of the indicated 1-mL fractions was Western-blotted against GFP. (C) Diagram of Bcl-xL, Bax, Bak, C-terminal truncation mutants of $\mathrm{Bax} / \mathrm{Bak}$, and the Bax/Bak-Bcl-xL chimeric proteins. $(D)$ Bcl-2 allKO cells carrying the Tet-on system expressing the GFP fusion proteins of the Bax/Bak wild type and mutants listed in $C$ were treated with $2 \mu \mathrm{g} / \mathrm{mL}$ Dox in the presence of $50 \mu \mathrm{M} \mathrm{z}$-VAD for $8 \mathrm{~h}$ before being fixed and stained for TOM20. $(E)$ The same cells as in $D$ were treated with $2 \mu \mathrm{g} / \mathrm{mL}$ Dox for $16 \mathrm{~h}$, lysed in buffer A with $2 \%$ CHAPS, and subjected to gel filtration analysis as described in $B .(F)$ Bcl-2 allKO cells used in $D$ and $E$ were induced by Dox in the presence or absence of $z$-VAD for the indicated time before being harvested and subjected to Western blot against GFP. $(G)$ DKO cells carrying the Tet-on-inducible expression system for the wild-type and mutant Bax/Bak were induced by Dox for the indicated times, lysed in buffer A with $2 \%$ CHAPS, and subjected to gel filtration analysis as described in $B$.

strongly suggest that mitochondrial association triggers Bax/Bak activation following neutralization of the antiapoptotic Bcl-2 family proteins.

\section{Discussion}

All proapoptotic BH3-only proteins are known to bind and neutralize the anti-apoptotic Bcl-2 proteins in response to various apoptotic stimuli (Willis and Adams 2005; Chipuk and Green 2008; Youle and Strasser 2008). In this study, we provide genetic evidence to suggest that, following inactivation of the anti-apoptotic Bcl-2 family proteins, the OMM-but not the BH3-only proteins, p53, or $\mathrm{Rb}$ - directly triggers Bax/Bak activation.

\section{$B H 3$-only proteins, $p 53$, and $R b$ are not necessary for a direct activation of $\mathrm{Bax} / \mathrm{Bak}$}

Mouse embryonic fibroblasts (MEFs) deficient for Bid, Bim, and Puma, the three major direct activator BH3- 
only proteins, have been previously generated and tested for their response to various apoptotic stimuli or overexpression of BH3-only proteins (Willis et al. 2007; Ren et al. 2010). However, due to the presence of additional putative direct activator $\mathrm{BH}$-only proteins (i.e., Noxa, Bmf, Bik, and Hrk) (Dai et al. 2011; Du et al. 2011), it has been difficult to assess the role of direct activation following inactivation of the anti-apoptotic Bcl-2 proteins in vivo. Using a cellular system in which all potential direct activator $\mathrm{BH} 3$-only proteins and the tumor suppressors $\mathrm{p} 53 / \mathrm{Rb}$ were eliminated, the present study demonstrated that the $\mathrm{BH}$-only proteins are not necessary for Bax/Bak activation once any combination of them successfully neutralizes Bcl-xL and Mcl-1 (Fig. 2-4). Likewise, the tumor suppressor p53 has been proposed to directly bind and activate $\mathrm{Bax} / \mathrm{Bak}$ after it is released from Bcl-xL's sequestration by the BH3-only protein Puma (Chipuk et al. 2004, 2005). However, the robust apoptosis in Octa/p53/Rb knockout cells following elimination/suppression of Bcl$\mathrm{xL} /$ Mcl-1 (Fig. 3) suggests that such a mechanism is not essential for Bax/Bak activation and supports the notion that p53-mediated transcriptional up-regulation of Puma/Noxa is sufficient for p53-dependent apoptosis (Jeffers et al. 2003; Villunger et al. 2003).

The observed BH3-only-independent Bax/Bak activation following neutralization of Bcl-xL/Mcl-1 (Figs. 2-4) is mostly consistent with the "indirect activation" model, which suggests that $\mathrm{BH} 3$-only proteins indirectly activate $\mathrm{Bax} / \mathrm{Bak}$ by inactivating the anti-apoptotic Bcl-2 proteins and releasing the active Bax/Bak molecules from their sequestration (Chen et al. 2005; Willis and Adams 2005; Willis et al. 2007). However, this model has difficulty in explaining the activation of Bax. Since Bax normally resides in the cytosol as an inactive monomer (Wolter et al. 1997), what is the direct trigger for Bax activation?

\section{Bax and Bak are both OMM proteins in the absence of other Bcl-2 family proteins}

Generation of Bcl-2 allKO cells allows one for the first time to examine the in vivo behavior of Bax/Bak in the absence of all other Bcl-2 proteins. Surprisingly, in Bcl-2 allKO cells, both Bax and Bak appeared to be membrane proteins that target to the OMM through their C-terminal tail (a9) without any stress signals (Fig. 6). This observation, combined with the membrane-dependent homo-oligomerization and the constitutive activities of Bax/Bak in these cells, eliminates the theoretical need for a "direct activator" outside the closed system of Bax/Bak-OMM.

The constitutive OMM localization of Bax in Bcl-2 allKO cells is consistent with results from Youle and coworkers (Edlich et al. 2011) that demonstrated that Bax has a tendency to constantly move to the OMM in healthy cells and that the prosurvival Bcl-2 proteins, such as Bcl$\mathrm{xL}$, possess a "retrotranslocation activity," shuttling Bax from the OMM to the cytosol. Interestingly, Bak was also found to be retrotranslocated by Bcl-xL, albeit at a much slower rate (Todt et al. 2015). Although the mechanism of retrotranslocation is not well understood, it is safe to suggest that the different abilities to be retrotranslo- cated by the anti-apoptotic Bcl-2 family proteins likely determine the differential subcellular localization of Bax and Bak before apoptotic stimulation.

It is conceivable that the cytosolic Bax molecules, presumably with their helix 9 constantly associating with and dissociating from the hydrophobic groove (Suzuki et al. 2000; Gahl et al. 2014), frequently collide with the OMM through free diffusion. While such a collision is likely not consequential in the presence of anti-apoptotic $\mathrm{Bcl}-2$ proteins, their inactivation by the $\mathrm{BH} 3$-only proteins and the concomitant loss of the retrotranslocation activities should allow helix 9 to anchor Bax to the OMM and trigger the membrane-mediated Bax/Bak activation.

\section{OMM as the direct activator of Bax/Bak following neutralization of anti-apoptotic Bcl-2 proteins}

The OMM has been suggested to be an active participant of MOMP by allowing or enhancing various interactions among Bcl-2 family proteins (Leber et al. 2007). How does OMM suddenly become an activator of Bax/Bak during apoptosis? Our data in OctaKO and Bcl-2 allKO cells suggest that, due to the $\mathrm{BH} 3$-only-mediated inactivation of anti-apoptotic Bcl-2 proteins but not the direct interaction with the $\mathrm{BH} 3$-only proteins, $\mathrm{p} 53$, or $\mathrm{Rb}$, both $\mathrm{Bax}$ and Bak gain full access to the OMM through their helix 9 (Fig. 6). After this initial anchoring, as can be speculated, other potential Bax/Bak-OMM interactions may help rearrange Bax/Bak helices and allow the formation of homo-oligomers through helices $\alpha 2-\alpha 5$. Consistent with this speculation, helices 4-6 of Bax have been found to associate with the OMM when they are individually expressed in the cells (George et al. 2010). Interestingly, several detergents have been found to cause conformational changes and activation of Bax/Bak (Hsu and Youle 1998). It is conceivable that these detergents to some extent mimic the actions of the OMM, and such stable lipid-protein interactions may help overcome a steep energy barrier to achieve Bax/Bak activation (Suzuki et al. 2000).

Although the OMM has traditionally been viewed as the target of Bax/Bak's destruction, our study provided evidence to suggest that it is also the primary, if not the only, direct instigator for such activities. Despite the fact that helices $\alpha 2-\alpha 5$ of Bax/Bak are the minimal structural unit sufficient for homo-oligomerization (George et al. 2007; Dai et al. 2011; Czabotar et al. 2013; Brouwer et al. 2014), the present study for the first time demonstrated the critical role of $\alpha 9$ in inducing $\mathrm{Bax} / \mathrm{Bak}^{\prime}$ s homo-oligomerization (Fig. 6). Our results suggest that $\alpha 9$ is the trigger site of Bax/ Bak and that a stable interaction between $\alpha 9$ and the OMM is sufficient to initiate the series of conformational changes and homo-oligomerization. Consistent with this conclusion, a recent study with reconstituted membranes suggested that, once in the membrane, Bax molecules form dimers, which further self-assemble into homo-oligomers (Subburaj et al. 2015). Furthermore, an $\alpha 9-\alpha 9$ interface was recently detected in the homo-oligomers of Bax and Bak (Bleicken et al. 2014; Gahl et al. 2014; Iyer et al. 2015). It can be speculated that, while the OMM lipids (e.g., cardiolipin, and sphingolipid products) are potential 
candidates to directly activate Bax/Bak, the protein components may play a modulatory role, as the OMM proteins Drp-1, OPA-1, Mfn1, etc., have been shown to play a role in MOMP (Scorrano et al. 2002; Montessuit et al. 2010; Renault et al. 2015). On the other hand, it will be important to understand how Bcl-xL/Mcl-1 interfere with the membrane-mediated self-assembly of Bax/Bak homo-oligomers. Nonetheless, the proposed role of OMM as the direct activator of $\mathrm{Bax} / \mathrm{Bak}$ for the first time suggested that MOMP is, in essence, a suicide of the OMM.

\section{Is there a role for Bok in MOMP after neutralization of anti-apoptotic Bcl-2 proteins?}

As Bok, an enigmatic Bcl-2 family protein, has recently been found to be expressed in HCT116 cells (Llambi et al. 2016), its potential role in the regulation of MOMP following suppression of the anti-apoptotic Bcl-2 proteins needs to be considered. Due to the presence of BH1-3 domains, Bok has been hypothesized to function as a Bax/ Bak-like effector protein (Hsu et al. 1997a). However, this hypothesis was not supported by the overwhelmingly strong apoptotic phenotype of Bax/Bak DKO cells /Wei et al. 2001). Recent data from Bok knockout and Bax/ Bak/Bok triple-knockout cells further demonstrated that Bok's apoptotic activity is Bax/Bak-dependent and that it does not play a role as an effector protein during MOMP (Echeverry et al. 2013; Ke et al. 2013; Carpio et al. 2015). Interestingly, a new study provided evidence to suggest that Bok is a noncanonical effector of MOMP in Bax/Bak DKO cells when its degradation is blocked by proteasome inhibition (Llambi et al. 2016). As shown in Figure 2, the loss of Bax and Bak completely abolished the robust apoptosis in DKO and OctaKO cells upon elimination of Bcl-xL and Mcl-1, excluding Bok's involvement as an effector under these conditions. Importantly, Bok's apoptotic activity is insensitive to suppression by anti-apoptotic Bcl-2 proteins (Llambi et al. 2016), suggesting that Bok's function and its regulation are independent of typical Bcl-2 family proteins. Thus, these findings strongly suggest that Bok does not function as an effector during BH3-only-mediated MOMP.

Based on Bok's Bax/Bak-dependent apoptotic activity, it has also been suggested that Bok may function as a BH3only protein (Echeverry et al. 2013; Carpio et al. 2015;). However, this proposition is in conflict with two important findings about Bok. First, Bok does not interact with the anti-apoptotic Bcl-2 proteins (Echeverry et al. 2013; Llambi et al. 2016). Second, the proapoptotic activity of Bok is not dependent on the presence of the $\mathrm{BH} 3$ domain (Echeverry et al. 2013). Collectively, these data appear to disqualify Bok as a proapoptotic BH3-only protein.

In summary, genetic knockout approaches combined with put-back experiments were used to demonstrate for the first time that, in the presence of OMM, both Bax and Bak are constitutively active without interference from the $\mathrm{BH} 3$-only proteins, the anti-apoptotic Bcl-2 family proteins, and the two tumor suppressors $\mathrm{p} 53 / \mathrm{Rb}$. We also demonstrated that the primary function of the $\mathrm{BH} 3$ only proteins in Bax/Bak activation is to inactivate or neu- tralize the anti-apoptotic Bcl-2 family proteins. Importantly, we found that the spontaneous association with the OMM provides the driving force for Bax/Bak activation following inactivation of anti-apoptotic Bcl-2 family proteins. Our data establish a "membrane-induced spontaneous Bax/Bak activation model" in which, upon BH3mediated inactivation of anti-apoptotic Bcl-2 proteins, the free diffusion-based, C-terminal tail ( $\alpha 9)$-mediated, spontaneous association of $\mathrm{Bax} / \mathrm{Bak}$ with the OMM directly triggers their activation (Fig. 7). Although more work is needed to delineate the cascade of conformational changes in the membrane following inactivation of the anti-apoptotic $\mathrm{Bcl}-2$ proteins and the initial membrane association during OMM-mediated Bax/Bak activation, our study supports the notion that the anti-apoptotic Bcl-2 family proteins and the OMM may be primary targets of therapeutic intervention aimed at potentiating or suppressing apoptosis.

It is also important to point out that, although the present study demonstrated that the direct interaction between BH3-only proteins and Bax/Bak is not essential for Bax/Bak activation, it did not exclude the possibility that such an interaction plays a role in modulating or fine-tuning the activation and activities of Bax and Bak in vivo. Future work is needed to further explore these possibilities.

Of note, a recent study presented data to suggest that, while Bax and Bak are directly activated by tBid, Bim, Puma, or Noxa, the activated Bax/Bak are suppressed by anti-apoptotic Bcl-2 proteins through complex formation but are liberated by the simultaneous suppression of Mcl-1 and Bcl-xL (Chen et al. 2015). In contrast, our data suggest that, following a $\mathrm{BH} 3$-only-mediated neutralization of the anti-apoptotic Bcl-2 proteins, Bax/Bak undergo spontaneous activation due to their affinity for the OMM, thus eliminating the need for a direct recruitment and

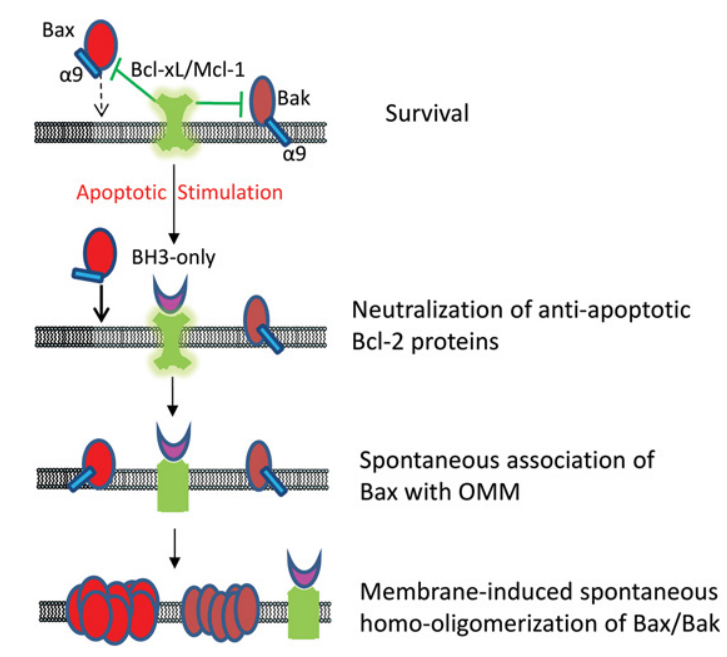

Figure 7. The membrane-induced spontaneous activation model for Bax/Bak. Following a BH3-only-mediated inactivation of anti-apoptotic Bcl-2 proteins, Bax spontaneously associated with the OMM through $\alpha 9$, and the OMM mediates homo-oligomerization of both Bax and Bak. 
activation of Bax/Bak by any $\mathrm{BH} 3$-only proteins as well as the need for preformed stable complexes between Bcl-xL/ Mcl-1 and Bax/Bak.

\section{Materials and methods}

\section{Cell culture}

HCT116 cells were purchased from American Type Culture Collection and cultured in McCoy's 5A medium supplemented with penicillin/streptomycin and 10\% fetal bovine serum (FBS) (Atlanta Biologicals, no. S11150). 293GP cells were cultured in DMEM medium supplemented with penicillin/streptomycin and 10\% FBS. All cells used in this study were maintained at $37^{\circ} \mathrm{C}$ with $5 \% \mathrm{CO}_{2}$.

\section{Reagents}

ABT-737 was purchased from Cayman Chemical. Human recombinant TRAIL was generated as previously described (Zhang et al. 2011). Thapsigargin was purchased from Adipogen. $z-\mathrm{VAD}(\mathrm{OMe})$ FMK was purchased from MP Biomedicals. Dox hydrochloride was purchased from Fisher Scientific. Propidium iodide solution was purchased from Biolegend. Crystal Violet was purchased from Fisher Scientific. The antibodies used included anti-Tom20 (Santa Cruz Biotechnology, no. sc-11415), anti-rabbit Alex fluor 594 (Molecular Probes, no. 11012), anti-Bcl-xl (Santa Cruz Biotechnology, no. sc-8392), anti-Bcl-2 (Santa Cruz Biotechnology, no. sc-509), anti-Mcl-1 (Santa Cruz Biotechnology, no. sc-819), anti-Bad (Santa Cruz Biotechnology, no. sc-8044), anti-Bim (Santa Cruz Biotechnology, no. sc-11425; Calbiochem, no. 202000), antiBid (Luo et al. 1998), anti-Bax (Santa Cruz Biotechnology, no. sc493), anti-p53 (Santa Cruz Biotechnology, no. sc-393), anti-RB (Santa Cruz Biotechnology, no. sc-50), anti-GFP (Santa Cruz Biotechnology, no. sc-459), anti-Bak (Santa Cruz Biotechnology, no. sc-832; Cell Signaling Technologies, no. 3814), anti-Bik (Santa Cruz Biotechnology, no. sc-365625), anti-Noxa (Santa Cruz Biotechnology, no. sc-56169; Imagenex Technologies Corp., no. IMG-349A), anti-Puma (Santa Cruz Biotehnology, no. sc-28226; Pro-Sci, 3041), anti-Bcl-w (Cell Signaling Technologies, no. 2724), anti-Bnip-3 (Cell Signaling Technologies, no. 13795), anti-Nix (Cell Signaling Technologies, no. 12396), anti-PARP (Cell Signaling Technologies, no. 9524), anti- $\beta$-actin (Sigma-Aldrich, no. A5441), and anti-TetR (Clonetech, no. 631131).

\section{Immunoblotting}

Harvested cells were lysed in EBC buffer (50 mM Tris, $120 \mathrm{mM}$ $\mathrm{NaCl}, 1 \mathrm{mM}$ EDTA, $0.5 \% \mathrm{NP} 40$ at $\mathrm{pH} 7.5$ ) supplemented with $0.1 \mathrm{mM}$ PMSF and protease inhibitors $(5 \mathrm{mg} / \mathrm{mL}$ pepstatin $\mathrm{A}, 10$ $\mathrm{mg} / \mathrm{mL}$ leupeptin) with a constant rotation for $1-2 \mathrm{~h}$ at $4^{\circ} \mathrm{C}$. Following centrifugation at $22,000 \mathrm{~g}$ for $10 \mathrm{~min}$ at $4^{\circ} \mathrm{C}$, supernatant was collected as the whole-cell lysate. The protein concentrations of the whole-cell lysates were measured using Commassie protein assay solution (Thermo Scientific, no. 1856209). Approximately $50 \mu \mathrm{g}$ of total protein from each whole-cell lysate was resolved by SDS-PAGE and transferred onto a nitrocellulose membrane before incubation with primary and secondary antibodies for Western blot. Proteins of interest were detected by chemiluminescence.

\section{Plasmids}

The TALEN expression vector for Bim was designed and constructed by Seoul National University, TALEN Library Resource (order no. H39213). A pair of DNA oligos for the sgRNA targeting site designed for gene and target regions of interest (Ran et al. $2013 \mathrm{~b}$ ) were annealed and ligated into Bbs1-cut px330 or px335 (AddGene, nos. 42230 and 42335). Oligo sequences cloned into px330 and px335 are in Supplemental Table S2.

Pairs of oligos containing the TALEN, CRISPR, or nickase recognition sites were ligated into EcoR1- and BamH1-cut reporter plasmid mRFP-TS-2A-HYG-EGFP (PNA Bio, Inc.). Sequences ligated into the mRFP-TS-2A-HYG-EGFP reporter plasmid included Mcl-1 (tctgGTAATAACACCAGTACGGACGGGtcac), Bcl-xl (ggcgACGAGTTTGAACTGCGGTACCGGcggg), Bcl-2 (AATT ctggGAGAACAGGGTACGATAACCGGGagatC), Bcl-w (AAT TtctgCCTCAGCTTATAACCTACAAAGTctgcC), Nix (AATT tcttTTGGATGCACAACATGAATCAGGacagC), Bnip-3 (AAT TgcacTTCAGCAATAATGGGAACGGGGGcagcC), A1 (AATT gtgcGTCCTACAGATACCACAACCTGGatcaC), Bax (tctcCT GCAGGATGATTGCCGCCGTGGacac), Bak (gggACGGCA GCTCGCCATCATCGGGGacga), Bid (CRISPR) (tgcaGCTCA TCGTAGCCCTCCCACTGGggag), Bid (nickase) (tcatCCGG AATATTGCCAGGCACCTCGcccaggtcggggacagCATGGACCG TAGCATCCCTCCGGgcct), Bim (CRISPR) gatcGCCCAAGAG TTGCG GCGTATTGGagac), Bim (TALEN) (TGACCGAGAA GGTAGACAATtgcagcetgcggAGAGGCCTCC CCAGCTCAGA), Puma (CRISPR) (ggggCGCTGGGCACGGGCGACTCCAGGtgtc), Puma (nickase) (gggcCCAGCTGCGGCGGATGGCGGACGA CCTCAACGCACAGTACGAGCGGcgg), Bad (ggggACGGAGG ACGACGAAGGGATGGGggag)， Bik (gcagAGACGCATTGG CCCTGCGGCTGGcctg), Noxa (gaagTCGAGTGTGCTACT CAACTCAGGaga), Bmf (ctcgATGTTGCCACTGCCCTTC GGGGGgctg), p53 (tgaaCCATTGTTCAATATCGTCCGGGG acaGCATCAAATCATC CATTGCTTGGgacg), and Rb1 (ataCC AGATCATGTCAGAGAGAGAGCttggttaacTTGGGAGAAA GTTTCATCTGTGGatgg).

The retroviral expression plasmids pMIG-GFP, pMIG-Bcl-xL, and pMIG-GFP-Bax were generated by ligating DNA fragments containing GFP, Bcl-xL, or GFP-Bax into the Xho1, Hind3-cut MSCV-IRES-GFP (pMIG) vector. The Xho1-Hind3 digestion eliminated the majority of the sequences encoding the endogenous IRES and GFP in pMIG. Human Bad and its BH3 mutant were PCR-amplified and ligated into pEFGP-C3 (Clontech, no. 6082-1) or pcFlag vector (modified from pcDNA3 vector for the inclusion of the Flag tag sequence) between the Xhol and EcoR1 sites. The resulting plasmids pEGFP-C3-Bad, pEGFP-C3$\mathrm{Bad}^{\mathrm{L} 114 \mathrm{E}}$, pcDNA3-Flag-Bad, and pcDNA3-Flag-Bad ${ }^{\mathrm{L} 114 \mathrm{E}}$ were used for transient transfection in Figure 6. pDsRed-Express-C1 (Clontech, no. 632430) was used in the cotransfection experiment (Fig. 6) marking the transfected cells. cDNAs for mouse Bax and human Bak were PCR-amplified and cloned into pEGFP-C3 vector (Clonetech) using XhoI and EcoR1 sites. Standard site-directed mutagenesis was used to generate Bax L63G/R64G and BakL78D mutants in pEGFP-C3. Enyzmes used for mutagenesis included Pfu polymerase (Stratagene) and Dpn1 (New England Biolabs) digestion. G-Bax, G-Bax $\Delta$ TM, G-Bak, and G-Bak $\Delta$ TM cDNAs were PCR-amplified from respective pEGFP-C3 constructs and cloned into pRetroX-Tight-Pur vector (Clonetech) using NotI and EcoR1 sites. Bax $\triangle T M$ consisted of amino acids 1-171, and Bak $\Delta T M$ consisted of amino acids 1-200. G-Bax $\Delta T M-C T(x L)$ and G-Bak $\Delta \mathrm{TM}-\mathrm{CT}(\mathrm{xL}) \mathrm{cDNAs}$ were constructed and amplified using PCR gene SOEing. Bax amino acids 1-170 and Bak amino acids 1-200 were fused with Bcl-xL residues 214-233. G-Bax $\Delta \mathrm{TM}-\mathrm{CT}(\mathrm{xL})$ and G-Bak $\Delta \mathrm{TM}-\mathrm{CT}(\mathrm{xL})$ were also cloned into pRetroX-Tight-Pur vector using NotI and EcoR1 sites.

\section{Plasmid transfection}

FugeneHD reagent (Promega, no. E2311) was used for transfection in HCT116 cells according to the manufacturer's instructions. 
For CRISPR and nickase transfections, $3 \times 10^{5}$ to $4 \times 10^{5}$ cells were seeded in a $35-\mathrm{mm}$ plate $24 \mathrm{~h}$ prior to transfection. Threehundred nanograms to $750 \mathrm{ng}$ of each CRISPR or nickase construct was cotransfected with $400 \mathrm{ng}$ of the corresponding mRFP-TS-2A-HYG-EGFP reporter plasmid. For the Bim TALEN transfection, $1.5 \mu \mathrm{g}$ of TALEN construct was used along with $400 \mathrm{ng}$ of mRFP-TS-2A-HYG-EGFP reporter. pcDNA3.1 was added to reach a total DNA concentration of $2 \mu \mathrm{g}$ per transfection. The transfected cells were split 1:2 $24 \mathrm{~h}$ later followed by $1 \mathrm{mg} /$ $\mathrm{mL}$ hygromycin B (Calbiochem, no. 400050) selection or flow cytometry sorting for RFP/GFP-positive cells. The FACS-sorted or hygromycin-selected cells were subsequently plated for single clones on 15-mm plates. FugeneHD was also used for transfection of wild-type or mutant HCT116 cells with Bad-expressing plasmids. Cells $\left(3 \times 10^{5}\right.$ to $\left.4 \times 10^{5}\right)$ were seeded in a $35-\mathrm{mm}$ plate $24 \mathrm{~h}$ prior to transfection. Five-hundred nanograms of each construct was used, with pcDNA3.1 added to maintain $1.5 \mu \mathrm{g}$ of total DNA per plate. Cells were analyzed 20-24 h after transfection.

\section{SiRNA transfection}

siRNA transfections were performed on $3 \times 10^{5}$ to $4 \times 10^{5}$ cells in $35-\mathrm{mm}$ culture dishes with antibiotic-free McCoy's $5 \mathrm{~A}$ medium supplemented with $10 \%$ FBS and DharmaFECT2 transfection reagent (Dharmacon, Inc., no. T-2002-01). On-Target Plus siMcl-1, siBcl-xL, or siControl (Dharmacon, Inc., nos. L-004501-00, L-003458-00, and D-001810-10-05) was suspended in 1× siRNA buffer (Dharmacon, Inc., no. B-002000-UB-100) and added to a plate at a final concentration of $22 \mathrm{nM}$. Cells transfected with either siBcl-xL or siMcl-1 individually were harvested 48-72 $\mathrm{h}$ after transfection for Western blot analysis. Double siRNA knockdown (Bcl-xL and Mcl-1) was performed sequentially. Cells were first transfected with siBcl-xL or siControl. Forty-eight hours later, cells were split 1:2, with one half transfected with Mcl-1 siRNA and the other with siControl. Twenty-four hours later, cells from the double-knockdown plates and the siControl plates were harvested for Western blot analysis with PARP antibody or stained by Hoechst dye for quantification of the condensed nuclei.

\section{Flow cytometry}

Transfected cells were sorted according to fluorescence on a BD FACSAria or a BD FACSAria II cell sorter with BD FACSDiva 6.1.2 software (Flow Cytometry Research Facility, University of Nebraska Medical Center). Cells with RFP and/or GFP signals were collected for plating.

\section{Retrovirus production}

pMIG, PIG, pRetroX-Tet-on Advanced, and pRetroX-Tight-Pur retroviruses were produced in 293GP packaging cells as previously described (Lopez et al. 2010). Virus infection was performed in HCT116 cells using $10 \mu \mathrm{g} / \mathrm{mL}$ polybrene (American Bioanalytical, no. AB01643).

\section{Inducible retroviral gene expression}

Advanced cell lines were made in DKO and Bcl-2 allKO cell lines by infection with pRetroX-Tet-on Advanced virus. Cells $\left(1 \times 10^{5}\right)$ were infected in a $35-\mathrm{mm}$ plate using a 1:1 ratio of virus and medium and $10 \mu \mathrm{g} / \mathrm{mL}$ polybrene. DKO-infected cells were selected with $2 \mathrm{mg} / \mathrm{mL}$ G418 for $14 \mathrm{~d}$. Bcl-2 allKO-infected cells were plated for single clones, and the single clones were screened for Tet-R expression via Western analysis. Advanced cell lines were subse- quently infected with pRetroX-Tight-Pur viruses containing the desired gene. Infected Bcl-2 allKO Adv cells were plated for single clones, and single clones were screened via $2-3 \mu \mathrm{g} / \mathrm{mL}$ Dox induction and GFP detection using a fluorescence microscope and Western analysis. Due to high infection efficiency and protein expression after Dox induction, DKO Adv pRetroX-Tight-Pur-infected pools were used for experiments.

\section{Genotyping}

Genomic DNA was isolated from HCT cells using DNeasy blood and tissue kit (Qiagen, no. 69504) and subjected to PCR to amplify genomic target regions of interest using Phusion or Taq polymerase (New England Biolabs, nos. E0553S and M0273L). PCR was performed according to the manufacturer's instructions for each polymerase, and thermocycler settings were adjusted according to product size and optimal primer annealing temperatures. Sequences for primers used for genomic PCR are in Supplemental Table S3. PCR products were cloned into the pGEM T-easy vector (Promega, no. A1360) using T4 ligase. Following transformation, blue/white selection (Fisher Scientific, no. BP4200-10) was used to enrich for colonies containing PCR inserts. Miniprep DNAs (Wizard Plus SV Minipreps DNA purification system; Promega, no. A1460) from the selected colonies were digested by EcoR 1 to determine the sizes of inserts. Plasmids with inserts were then sent for Sanger sequencing using T7 or SP6 primers (High-Throughput DNA Sequencing and Genotyping Core Facility, University of Nebraska Medical Center). In addition, if the genomic PCR reaction yielded a single PCR product on the agarose gel, primers from the original PCR or inner primers were used to directly sequence the PCR product to confirm the results from the corresponding pGEM clones.

\section{cDNA amplification and analysis}

RNA from HCT116 wild-type cells, each of the three OctaKO clones, and both Bcl-2 allKO clones was isolated with TRIzol reagent (Invitrogen, no. 1304078) following the manufacturer's instructions. Total cDNA was made from each RNA sample using the GoScript reverse transcriptase system (Promega, no. A5000) with the oligo(dT) primer according to the manufacturer's instructions. The total cDNAs from the wild-type and OctaKO cell lines were used as templates to amplify cDNAs of Bmf and Hrk with gene-specific primers. The forward and reverse primers for Bmf and Hrk cDNA were designed in different exons to ensure that amplification of CRISPR target regions was from cDNA but not from contaminating genomic DNA. The primers used for Bmf cDNA were outer (F-GATGGAGCCATCTCAGTGTGTG and R-GTTCCTGGTGCCCCATGTG) and nested (F-GGAGCTGG AGGATGATGTGT and R-TTCAAAGCAAGGTTGTGCAG). The primers used for Hrk cDNA were outer (F-CACAAGGAG AAACTTGGTG and R-GCAAGGTGCAGAAAAGGAAG) and nested (F-AACTTGGTGTCCAGGGGAG and R-CGATCG CTCCAGGCGCTG). Bmf and Hrk PCR products from the cDNA amplification were cloned into pGEM T-easy and subjected to Sanger sequencing as described above in the "Genotyping" section. The total cDNAs from wild-type and Bcl-2 allKO cell lines were used as templates to amplify cDNAs $\beta$-actin and Bcl-xL using gene-specific primers. $\beta$-Actin primers were used to ensure the quality of cDNA, and Bcl-xL primers were used to detect the presence of messenger RNA in Bcl-2 allKO clones by amplifying the full cDNA sequence of Bcl-xL. The primers used for $\beta$-actin were F-CCTCGCCTTTGCCGATCC and R-GGATCTTCATGAGGTAGTCAGTC. The primers used for Bcl-xl were 
F-CAGTGAATTCATGTCTCAGAGCAACCGGGAGCTG and R-CAGTCTCGAGTCATTTCCGACTGAAGAGTGAGCC.

\section{Apoptosis assays}

Cells $\left(4 \times 10^{5}\right.$ to $\left.5 \times 10^{5}\right)$ were seeded in $35-\mathrm{mm}$ plates $16-20 \mathrm{~h}$ prior to apoptosis treatments. Cells were treated with $3 \mu \mathrm{M}$ thapsigargin for $24 \mathrm{~h}$, human recombinant $25 \mathrm{ng} / \mathrm{mL}$ TRAIL for $5 \mathrm{~h}$, or $2.5 \mu \mathrm{M}$ ABT -737 for $16 \mathrm{~h}$ before being harvested for analysis. Cells were also treated with $500 \mathrm{~J} / \mathrm{M}^{2} \mathrm{UV}$ or $500 \mathrm{~J} / \mathrm{M}^{2} \mathrm{UV}-\mathrm{ABT}-737$ (with $2.5 \mu \mathrm{M}$ ABT-737 added immediately following UV treatment) and were harvested for analysis $16 \mathrm{~h}$ later. For serum starvation, the culture medium from cells seeded the previous day was completely removed and replaced by McCoy's $5 \mathrm{~A}$ medium without FBS. These cells were cultured for another $48 \mathrm{~h}$ before being collected for analysis by either FACS or Western blot against PARP. For Annexin V staining, treated cells were collected from medium in plates and trypsination of attached cells in plates. Cells were stained with FITC Annexin V or APC Annexin V (Biolegend, nos. 640906 and 640920) according to manufacturer's instructions. Ten-thousand cells from each sample were analyzed for FITC signal by flow cytometry. Cell counting and analysis were performed on a BD FACSCalibur flow cytometer with BD FACSDiva 8.0 software (Flow Cytometry Research Facility, University of Nebraska Medical Center). For detection of PARP cleavage in treated samples, whole-cell lysates were prepared as described above and subjected to Western blot with PARP antibody.

\section{Apoptosis quantification}

Quantification of apoptotic cells according to nuclear morphology was performed as previously described (George et al. 2007). Cells were stained with $1 \mu \mathrm{g} / \mathrm{mL}$ Hoechst 33342 (Molecular Probes, no. H-3570) for $10 \mathrm{~min}$ at $37^{\circ} \mathrm{C}$. Pictures of three random viewing areas were taken for each plate. The percentage of cells undergoing nuclear condensation was determined for each viewing area. At least two independent experiments were performed for each transfection.

\section{Caspase 3/7 activity assay}

Cells were seeded in a 96-well plate at a concentration of $8 \times 10^{3}$ to $10 \times 10^{3}$ cells per well $40 \mathrm{~h}$ prior to treatment. After treatment, $50 \mu \mathrm{L}$ of Apo-ONE Caspase 3/7 reagent (Promega, no. G7790) was added to $70 \mu \mathrm{L}$ of medium in each well. Plates were rocked in the dark for $20 \mathrm{~min}$ and then frozen at $-80^{\circ} \mathrm{C}$ before being thawed to achieve complete cell lysis. Plates were analyzed on a POLARstar Optima microplate reader (BMG Labtech) at 485-nm excitation and 520 emission.

\section{Mitochondrial staining}

MitoTracker Red CMXRos (Life Technologies, no. M7512) was added to cells cultured on coverslips at a final concentration of $50 \mathrm{nM}$. Following incubation for $5 \mathrm{~min}$ at $37^{\circ} \mathrm{C}$, coverslips were mounted on slides, sealed, and photographed under a fluorescence microscope (Nickon Eclipse 50i). Immunostaining was performed using Tom-20 primary antibody and anti-rabbit Alexa fluor 594 secondary antibody. Cells were plated on chamber slides and fixed with $3 \%$ paraformaldehyde, permeabilized with $0.15 \%$ Triton X-100 in PBS, and blocked with $2 \%$ BSA in PBS prior to antibody staining. After staining, coverslips were mounted and sealed on slides, and cells were then photographed under a fluorescence microscope (Nickon Eclipse 50i).

\section{Bax translocation assay}

Octa/Mcl-1/Bax/Bak knockout/GFP-Bax cells were cotransfected with pDsRED and either pcFlag, pcFlag-Bad, or pcFlag-Bad ${ }^{\mathrm{L} 114 \mathrm{E}}$. $z$-VAD-FMK $(20 \mu \mathrm{M})$ was added to plates immediately prior to transfection. Twenty-four hours after transfection, pictures capturing six views from each plate were taken. Cells in each view were then counted for the presence of RFP signal (marking the transfected cells) and the punctate GFP staining (marking the cells with GFP-Bax mitochondrial translocation). Cell counts from each plate were combined to calculate the percent of transfected cells with Bax translocation. Counts from two independent experiments were used.

\section{Gel filtration analysis}

pRetro Adv cell lines were induced for $16 \mathrm{~h}$ using $2 \mu \mathrm{g} / \mathrm{mL}$ Dox. Bcl-2 allKO cells carrying pRetro Bax, Bak, Bax-xL, and Bak-xL were induced in the presence of $20 \mu \mathrm{M} \mathrm{z}$-VAD. Whole-cell lysates were obtained and lysed in lysis buffer (buffer A + $2 \%$ CHAPS; buffer A consisted of $20 \mathrm{mM}$ HEPES-KOH, $10 \mathrm{mM} \mathrm{KCL}, 1.5$ $\mathrm{mM} \mathrm{MgCl} 2,1 \mathrm{mM}$ sodium EDTA, $1 \mathrm{mM}$ sodium EGTA, $1 \mathrm{mM}$ dithiothreitol [DTT], 0.1 PMSF, $5 \mathrm{mg} / \mathrm{mL}$ pepstatin A, $10 \mathrm{mg} /$ $\mathrm{mL}$ leupeptin). Lysates were rotated for $30-60 \mathrm{~min}$ at $4^{\circ} \mathrm{C}$ and then centrifuged at $25,000 \mathrm{~g}$ for $15 \mathrm{~min}$ at $4^{\circ} \mathrm{C}$. The supernatant containing 1-2 $\mathrm{mg} / \mathrm{mL}$ protein was then loaded on a FPLC Superdex 200 10/30 column equilibrated with $100 \mathrm{mM} \mathrm{NaCL}$ in buffer A with $2 \%$ CHAPS. Fractions were eluted at $0.5 \mathrm{~mL}$ per minute and collected as $1-\mathrm{mL}$ factions. Thirty microliters of each fraction was loaded on SDS-PAGE and transferred to nitrocellulose membrane after electrophoresis. Western blot analysis was then performed to detect GFP-tagged proteins.

\section{FACS cell cycle analysis}

HCT116 cells $\left(2 \times 10^{6}\right)$ in 60 -mm plates were washed with PBS and fixed with $70 \%$ ethanol. After fixing, cells were incubated in Telford reagent $(0.1 \mathrm{mM}$ EDTA, $0.03 \mathrm{mg} / \mathrm{mL}$ RNase A, 0.05 $\mathrm{mg} / \mathrm{mL}$ propidium iodide, $0.1 \%$ Triton X-100 in PBS) for $30-60$ min on ice. Cells were then strained and analyzed for cell cycle phase using BD FACSCalibur flow cytometer and ModFit LT analysis software (Flow Cytometry Research Facility, University of Nebraska Medical Center).

\section{Cell growth assay}

Cells were plated at a concentration of 50,000 cells per plate. Every $24 \mathrm{~h}$ for six consecutive days, cells were trypsinized, centrifuged, resuspended, and counted on a hemocytometer to determine the number of cells per plate.

\section{Clonogenic survival assays}

Cells were plated at $4 \times 10^{5}$ per $35-\mathrm{mm}$ plate $1 \mathrm{~d}$ prior to treatment. After treatment, cells were trypsinized, centrifuged, and serially diluted, and dilutions were placed separately in $10-\mathrm{cm}$ plates. Eight days after plating, medium was removed, and cells were stained for $30 \mathrm{~min}$ at room temperature with Crystal Violet fixing/staining solution $10.05 \%$ Crystal Violet, $1 \%$ formaldehyde, $1 \%$ methanol in $1 \times$ PBS solution). Fixing/staining solution was then removed, and plates were dipped in water to remove excess Crystal Violet. 


\section{Acknowledgments}

We are grateful for the University of Nebraska Medical Center Mouse Genome Engineering Core facility, especially Rolen Quadros and Dr. Channabasavaiah Gurumurthy, for their technical support, helpful discussions, and advice. We are also grateful for the University of Nebraska Medical Center DNA Sequencing and Flow Cytometry facilities, especially Victoria Smith, Samantha Wall, and Dr. Philip Hexley, for their excellent technical support. We thank Dr. David Kelly for his help with fluorescence reading of the caspase substrate assay. This work was supported by a pilot grant from the Nebraska Center for Cellular Signaling (P20-GM103489) and Nebraska Research Initiative Funds to X.L.

\section{References}

Bleicken S, Jeschke G, Stegmueller C, Salvador-Gallego R, Garcia-Saez AJ, Bordignon E. 2014. Structural model of active Bax at the membrane. Mol Cell 56: 496-505.

Borner C, Andrews DW. 2014. The apoptotic pore on mitochondria: are we breaking through or still stuck? Cell Death Differ 21: 187-191.

Brouwer JM, Westphal D, Dewson G, Robin AY, Uren RT, Bartolo R, Thompson GV, Colman PM, Kluck RM, Czabotar PE. 2014. Bak core and latch domains separate during activation, and freed core domains form symmetric homodimers. Mol Cell 55: 938-946.

Carpio MA, Michaud M, Zhou W, Fisher JK, Walensky LD, Katz SG. 2015. BCL-2 family member BOK promotes apoptosis in response to endoplasmic reticulum stress. Proc Natl Acad Sci 112: 7201-7206.

Chen L, Willis SN, Wei A, Smith BJ, Fletcher JI, Hinds MG, Colman PM, Day CL, Adams JM, Huang DC. 2005. Differential targeting of prosurvival Bcl-2 proteins by their BH3-only ligands allows complementary apoptotic function. Mol Cell 17: 393-403.

Chen HC, Kanai M, Inoue-Yamauchi A, Tu HC, Huang Y, Ren D, Kim H, Takeda S, Reyna DE, Chan PM, et al. 2015. An interconnected hierarchical model of cell death regulation by the BCL-2 family. Nat Cell Biol 17: 1270-1281.

Chipuk JE, Green DR. 2008. How do BCL-2 proteins induce mitochondrial outer membrane permeabilization? Trends Cell Biol 18: 157-164.

Chipuk JE, Kuwana T, Bouchier-Hayes L, Droin NM, Newmeyer DD, Schuler M, Green DR. 2004. Direct activation of Bax by p53 mediates mitochondrial membrane permeabilization and apoptosis. Science 303: 1010-1014.

Chipuk JE, Bouchier-Hayes L, Kuwana T, Newmeyer DD, Green DR. 2005. PUMA couples the nuclear and cytoplasmic proapoptotic function of p53. Science 309: 1732-1735.

Czabotar PE, Westphal D, Dewson G, Ma S, Hockings C, Fairlie WD, Lee EF, Yao S, Robin AY, Smith BJ, et al. 2013. Bax crystal structures reveal how $\mathrm{BH} 3$ domains activate $\mathrm{Bax}$ and nucleate its oligomerization to induce apoptosis. Cell 152: 519-531.

Dai H, Smith A, Meng XW, Schneider PA, Pang YP, Kaufmann SH. 2011. Transient binding of an activator BH3 domain to the Bak BH3-binding groove initiates Bak oligomerization. I Cell Biol 194: 39-48.

Du H, Wolf J, Schafer B, Moldoveanu T, Chipuk JE, Kuwana T. 2011. BH3 domains other than Bim and Bid can directly activate Bax/Bak. J Biol Chem 286: 491-501.

Echeverry N, Bachmann D, Ke F, Strasser A, Simon HU, Kaufmann T. 2013. Intracellular localization of the BCL-2 family member BOK and functional implications. Cell Death Differ 20: 785-799.

Edlich F, Banerjee S, Suzuki M, Cleland MM, Arnoult D, Wang C, Neutzner A, Tjandra N, Youle RJ. 2011. Bcl-x(L) retrotranslocates Bax from the mitochondria into the cytosol. Cell 145: 104-116.

Fletcher JI, Meusburger S, Hawkins CI, Riglar DT, Lee EF, Fairlie WD, Huang DC, Adams JM. 2008. Apoptosis is triggered when prosurvival Bcl-2 proteins cannot restrain Bax. Proc Natl Acad Sci 105: 18081-18087.

Fuchs Y, Steller H. 2011. Programmed cell death in animal development and disease. Cell 147: 742-758.

Gahl RF, He Y, Yu S, Tjandra N. 2014. Conformational rearrangements in the pro-apoptotic protein, Bax, as it inserts into mitochondria: a cellular death switch. I Biol Chem 289: 32871-32882.

Garcia-Saez AJ. 2012. The secrets of the Bcl-2 family. Cell Death Differ 19: 1733-1740.

Gavathiotis E, Suzuki M, Davis ML, Pitter K, Bird GH, Katz SG, Tu HC, Kim H, Cheng EH, Tjandra N, et al. 2008. BAX activation is initiated at a novel interaction site. Nature 455: 1076-1081.

George NM, Evans JJ, Luo X. 2007. A three-helix homo-oligomerization domain containing $\mathrm{BH} 3$ and $\mathrm{BH} 1$ is responsible for the apoptotic activity of Bax. Genes Dev 21: 1937-1948.

George NM, Targy N, Evans JJ, Zhang L, Luo X. 2010. Bax contains two functional mitochondrial targeting sequences and translocates to mitochondria in a conformational changeand homo-oligomerization-driven process. I Biol Chem 285: 1384-1392.

Hilgendorf KI, Leshchiner ES, Nedelcu S, Maynard MA, Calo E, Ianari A, Walensky LD, Lees JA. 2013. The retinoblastoma protein induces apoptosis directly at the mitochondria. Genes Dev 27: 1003-1015.

Hsu YT, Youle RJ. 1998. Bax in murine thymus is a soluble monomeric protein that displays differential detergent-induced conformations. J Biol Chem 273: 10777-10783.

Hsu SY, Kaipia A, McGee E, Lomeli M, Hsueh AJ. 1997a. Bok is a pro-apoptotic Bcl-2 protein with restricted expression in reproductive tissues and heterodimerizes with selective anti-apoptotic Bcl-2 family members. Proc Natl Acad Sci 94: 12401-12406.

Hsu YT, Wolter KG, Youle RJ. 1997b. Cytosol-to-membrane redistribution of Bax and Bcl-X(L) during apoptosis. Proc Natl Acad Sci 94: 3668-3672.

Iyer S, Bell F, Westphal D, Anwari K, Gulbis J, Smith BJ, Dewson G, Kluck RM. 2015. Bak apoptotic pores involve a flexible Cterminal region and juxtaposition of the C-terminal transmembrane domains. Cell Death Differ 22: 1665-1675.

Jeffers JR, Parganas E, Lee Y, Yang C, Wang J, Brennan J, MacLean KH, Han J, Chittenden T, Ihle JN, et al. 2003. Puma is an essential mediator of $\mathrm{p} 53$-dependent and -independent apoptotic pathways. Cancer Cell 4: 321-328.

Jiang X, Wang X. 2004. Cytochrome c-mediated apoptosis. Annu Rev Biochem 73: 87-106.

Kaufmann T, Schlipf S, Sanz J, Neubert K, Stein R, Borner C. 2003. Characterization of the signal that directs $\mathrm{Bcl}-\mathrm{x}(\mathrm{L})$, but not Bcl-2, to the mitochondrial outer membrane. I Cell Biol 160: 53-64.

Ke F, Bouillet P, Kaufmann T, Strasser A, Kerr J, Voss AK. 2013. Consequences of the combined loss of $\mathrm{BOK}$ and $\mathrm{BAK}$ or BOK and BAX. Cell Death Dis 4: e650.

Kim H, Rafiuddin-Shah M, Tu HC, Jeffers JR, Zambetti GP, Hsieh JJ, Cheng EH. 2006. Hierarchical regulation of mitochondrion- 
dependent apoptosis by BCL-2 subfamilies. Nat Cell Biol 8: 1348-1358.

Kim H, Tu HC, Ren D, Takeuchi O, Jeffers JR, Zambetti GP, Hsieh JJ, Cheng EH. 2009. Stepwise activation of BAX and BAK by tBID, BIM, and PUMA initiates mitochondrial apoptosis. Mol Cell 36: 487-499.

Leber B, Lin J, Andrews DW. 2007. Embedded together: the life and death consequences of interaction of the Bcl-2 family with membranes. Apoptosis 12: 897-911.

Letai A, Bassik MC, Walensky LD, Sorcinelli MD, Weiler S, Korsmeyer SJ. 2002. Distinct BH3 domains either sensitize or activate mitochondrial apoptosis, serving as prototype cancer therapeutics. Cancer Cell 2: 183-192.

Li H, Zhu H, Xu CJ, Yuan J. 1998. Cleavage of BID by caspase 8 mediates the mitochondrial damage in the Fas pathway of apoptosis. Cell 94: 491-501.

Llambi F, Moldoveanu T, Tait SW, Bouchier-Hayes L, Temirov J, McCormick LL, Dillon CP, Green DR. 2011. A unified model of mammalian BCL-2 protein family interactions at the mitochondria. Mol Cell 44: 517-531.

Llambi F, Wang YM, Victor B, Yang M, Schneider DM, Gingras S, Parsons MJ, Zheng JH, Brown SA, Pelletier S, et al.. 2016. BOK is a non-canonical BCL-2 family effector of apoptosis regulated by ER-associated degradation. Cell doi: 10.1016/ j.cell.2016.02.026.

Lopez H, Zhang L, George NM, Liu X, Pang X, Evans JJ, Targy NM, Luo X. 2010. Perturbation of the Bcl-2 network and an induced Noxa/Bcl-xL interaction trigger mitochondrial dysfunction after DNA damage. J Biol Chem 285: 15016-15026.

Luo X, Budihardjo I, Zou H, Slaughter C, Wang X. 1998. Bid, a Bcl2 interacting protein, mediates cytochrome $\mathrm{c}$ release from mitochondria in response to activation of cell surface death receptors. Cell 94: 481-490.

Mali P, Aach J, Stranges PB, Esvelt KM, Moosburner M, Kosuri S, Yang L, Church GM. 2013. CAS9 transcriptional activators for target specificity screening and paired nickases for cooperative genome engineering. Nat Biotechnol 31: 833-838.

Moldoveanu T, Grace CR, Llambi F, Nourse A, Fitzgerald P, Gehring K, Kriwacki RW, Green DR. 2013. BID-induced structural changes in BAK promote apoptosis. Nat Struct Mol Biol 20: 589-597.

Moldoveanu T, Follis AV, Kriwacki RW, Green DR. 2014. Many players in BCL-2 family affairs. Trends Biochem Sci 39: $101-111$

Montessuit S, Somasekharan SP, Terrones O, Lucken-Ardjomande S, Herzig S, Schwarzenbacher R, Manstein DJ, BossyWetzel E, Basanez G, Meda P, et al. 2010. Membrane remodeling induced by the dynamin-related protein Drp1 stimulates Bax oligomerization. Cell 142: 889-901.

Nijhawan D, Fang M, Traer E, Zhong Q, Gao W, Du F, Wang X. 2003. Elimination of Mcl-1 is required for the initiation of apoptosis following ultraviolet irradiation. Genes Dev 17: 1475-1486.

Oltersdorf T, Elmore SW, Shoemaker AR, Armstrong RC, Augeri DJ, Belli BA, Bruncko M, Deckwerth TL, Dinges J, Hajduk PJ, et al. 2005. An inhibitor of Bcl-2 family proteins induces regression of solid tumours. Nature 435: 677-681.

Puthalakath H, O'Reilly LA, Gunn P, Lee L, Kelly PN, Huntington ND, Hughes PD, Michalak EM, McKimm-Breschkin J, Motoyama N, et al. 2007. ER stress triggers apoptosis by activating BH3-only protein Bim. Cell 129: 1337-1349.

Ran FA, Hsu PD, Lin CY, Gootenberg JS, Konermann S, Trevino AE, Scott DA, Inoue A, Matoba S, Zhang Y, et al. 2013a. Dou- ble nicking by RNA-guided CRISPR Cas9 for enhanced genome editing specificity. Cell 154: 1380-1389.

Ran FA, Hsu PD, Wright J, Agarwala V, Scott DA, Zhang F. 2013b. Genome engineering using the CRISPR-Cas9 system. Nat Protoc 8: 2281-2308.

Ren D, Tu HC, Kim H, Wang GX, Bean GR, Takeuchi O, Jeffers JR, Zambetti GP, Hsieh JJ, Cheng EH. 2010. BID, BIM, and PUMA are essential for activation of the BAX- and BAK-dependent cell death program. Science 330: 1390-1393.

Renault TT, Floros KV, Elkholi R, Corrigan KA, Kushnareva Y, Wieder SY, Lindtner C, Serasinghe MN, Asciolla JJ, Buettner C, et al. 2015. Mitochondrial shape governs BAX-induced membrane permeabilization and apoptosis. Mol Cell 57: 69-82.

Scorrano L, Ashiya M, Buttle K, Weiler S, Oakes SA, Mannella CA, Korsmeyer SJ. 2002. A distinct pathway remodels mitochondrial cristae and mobilizes cytochrome c during apoptosis. Dev Cell 2: 55-67.

Subburaj Y, Cosentino K, Axmann M, Pedrueza-Villalmanzo E, Hermann E, Bleicken S, Spatz J, Garcia-Saez AJ. 2015. Bax monomers form dimer units in the membrane that further self-assemble into multiple oligomeric species. Nat Commun 6: 8042 .

Suzuki M, Youle RJ, Tjandra N. 2000. Structure of Bax: coregulation of dimer formation and intracellular localization. Cell 103: 645-654.

Tait SW, Green DR. 2010. Mitochondria and cell death: outer membrane permeabilization and beyond. Nat Rev Mol Cell Biol 11: 621-632.

Todt F, Cakir Z, Reichenbach F, Emschermann F, Lauterwasser J, Kaiser A, Ichim G, Tait SW, Frank S, Langer HF, et al. 2015. Differential retrotranslocation of mitochondrial Bax and Bak. ЕMBO J 34: 67-80.

Villunger A, Michalak EM, Coultas L, Mullauer F, Bock G, Ausserlechner MJ, Adams JM, Strasser A. 2003. p53- and drug-induced apoptotic responses mediated by $\mathrm{BH} 3$-only proteins puma and noxa. Science 302: 1036-1038.

Walensky LD, Gavathiotis E. 2011. BAX unleashed: the biochemical transformation of an inactive cytosolic monomer into a toxic mitochondrial pore. Trends Biochem Sci 36: 642-652.

Wei MC, Zong WX, Cheng EH, Lindsten T, Panoutsakopoulou V, Ross AJ, Roth KA, MacGregor GR, Thompson CB, Korsmeyer SJ. 2001. Proapoptotic BAX and BAK: a requisite gateway to mitochondrial dysfunction and death. Science 292: 727-730.

Willis SN, Adams JM. 2005. Life in the balance: how BH3-only proteins induce apoptosis. Curr Opin Cell Biol 17: 617-625.

Willis SN, Fletcher II, Kaufmann T, van Delft MF, Chen L, Czabo$\operatorname{tar}$ PE, Ierino H, Lee EF, Fairlie WD, Bouillet P, et al. 2007. Apoptosis initiated when $\mathrm{BH} 3$ ligands engage multiple Bcl-2 homologs, not Bax or Bak. Science 315: 856-859.

Wolter KG, Hsu YT, Smith CL, Nechushtan A, Xi XG, Youle RJ. 1997. Movement of Bax from the cytosol to mitochondria during apoptosis. J Cell Biol 139: 1281-1292.

Youle RJ, Strasser A. 2008. The BCL-2 protein family: opposing activities that mediate cell death. Nat Rev Mol Cell Biol 9: 47-59.

Zhang L, Lopez H, George NM, Liu X, Pang X, Luo X. 2011. Selective involvement of $\mathrm{BH} 3$-only proteins and differential targets of Noxa in diverse apoptotic pathways. Cell Death Differ 18: 864-873. 


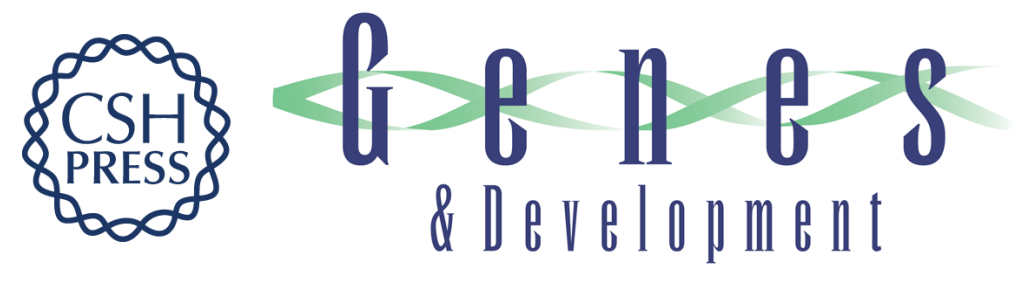

\section{Inactivation of prosurvival Bcl-2 proteins activates Bax/Bak through the outer mitochondrial membrane}

Katelyn L. O'Neill, Kai Huang, Jingjing Zhang, et al.

Genes Dev. 2016, 30: originally published online April 7, 2016

Access the most recent version at doi:10.1101/gad.276725.115

\section{Supplemental http://genesdev.cshlp.org/content/suppl/2016/04/07/gad.276725.115.DC1 \\ Material}

Related Content

MOMP in the absence of BH3-only proteins

Ana J. García Sáez and Andreas Villunger

Genes Dev. April , 2016 30: 878-880

References This article cites 63 articles, 21 of which can be accessed free at:

http://genesdev.cshlp.org/content/30/8/973.full.html\#ref-list-1

Articles cited in:

http://genesdev.cshlp.org/content/30/8/973.full.html\#related-urls

Creative This article is distributed exclusively by Cold Spring Harbor Laboratory Press for the first Commons

License

six months after the full-issue publication date (see

http://genesdev.cshlp.org/site/misc/terms.xhtml). After six months, it is available under a Creative Commons License (Attribution-NonCommercial 4.0 International), as described at http://creativecommons.org/licenses/by-nc/4.0/.

Email Alerting

Receive free email alerts when new articles cite this article - sign up in the box at the top

Service right corner of the article or click here.

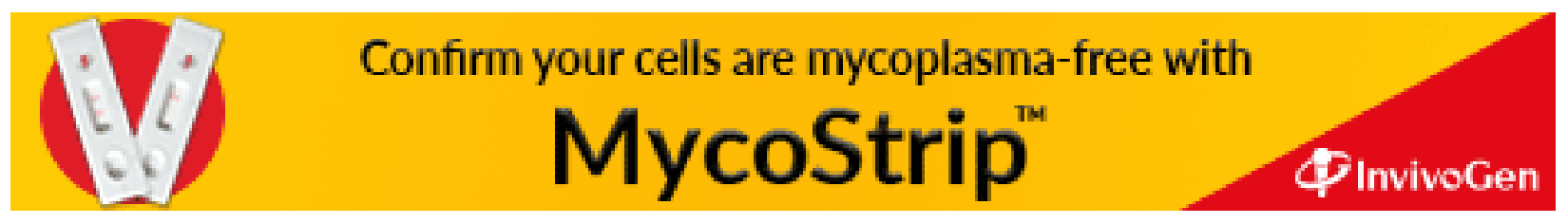

